VAN WEEZEL, Alex. "El delito de infracción de una patente por equivalencia o por imitación".

Polít. crim. Vol. 8, No 15 (Julio 2013), Art. 5, pp. 170 - 209.

[http://www.politicacriminal.cl/Vol_08/n_15/Vol8N15A5.pdf]

\title{
El delito de infracción de una patente por equivalencia o por imitación
}

\author{
Prof. Dr. Alex van Weezel* \\ Pontificia Universidad Católica de Chile \\ avw@uc.cl
}

\section{Resumen}

La doctrina de los equivalentes y sus limitaciones configuran de un modo determinante el equilibrio entre la certeza de la protección que brinda una patente y la restricción de dicha protección que resulta indispensable para el bien común. Este equilibrio se encuentra en la base del sistema de la propiedad industrial y la tensión entre sus dos extremos caracteriza al bien jurídico protegido por los delitos de infracción de una patente. El presente trabajo procura mostrar, a la luz del derecho comparado, la relevancia de esta doctrina para la interpretación de los tipos penales previstos en el art. 52 de la Ley 19.039, concretamente en lo que respecta las expresiones "invento patentado", "procedimiento patentado" e "imiten un invento con solicitud de patente en trámite", cuando se trata contrastar el invento o procedimiento patentado (o con solicitud de patente en trámite) con un invento o procedimiento presuntamente infractor.

\section{Palabras clave}

Patente de invención, doctrina de los equivalentes, delitos contra la propiedad industrial, interpretación de reivindicaciones, arte previo.

\begin{abstract}
The doctrine of equivalents and its limitations are a determining element in the balance between the certainty of the protection granted by a patent and the restriction of such protection so far as it is convenient for the community. This balance is at the base of the industrial property system and the tension between its two ends characterizes the legally protected object in the crimes of patent infringement. This paper seeks to show, in the light of comparative law, the relevance of this doctrine for the interpretation of the crimes under Article 52 of Law Nr. 19.039, in particular as regards the terms "patented invention", "patented process" and "imitate an invention patent application pending" when it comes to contrast a patented (or patent application pending) invention or process with an allegedly infringing invention or process.
\end{abstract}

\footnotetext{
* El autor agradece los comentarios y sugerencias de Felipe Claro Swinburn desde la perspectiva del derecho de propiedad industrial, y la valiosa ayuda de Johanna van der Henst en la sistematización del material jurisprudencial estadounidense.
} 
VAN WEEZEL, Alex. "El delito de infracción de una patente

por equivalencia o por imitación”.

\section{Key words}

Patent, doctrine of equivalents, crimes against intellectual property, patent claims interpretation, prior art.

\section{Introducción}

Los derechos denominados en conjunto como "propiedad industrial", incluyendo aquellos que adoptan la forma de patentes de invención, siguen siendo objeto de viva discusión en cuanto a su contenido y alcance. Desde la perspectiva del análisis económico del derecho, se ha desarrollado una visión que caracteriza al bien jurídico protegido por una patente como el resultado de una tensión permanente entre la difusión universal del conocimiento y los incentivos para el que se arriesga a innovar, destinando a ello capital y trabajo que podría haber empleado de otro modo. Se trata de incentivar al inventor, permitiéndole recuperar sus costos y obtener una ganancia, sin que ello impida poner a disposición de toda la comunidad los avances tecnológicos.

Desde este punto de vista, la protección que brinda la patente será eficiente en la medida en que el propietario pueda internalizar la totalidad de las externalidades, tanto positivas como negativas, asociadas a la invención. ${ }^{1}$ Por lo tanto, y guardando las distancias - pues desde el punto de vista económico los derechos sobre el conocimiento constituyen propiedad sólo en un sentido análogo o extendido-, la eficiencia requiere un régimen asimilable al de la propiedad, que defina con precisión el alcance de la protección que brinda la patente y, como contrapartida, los contornos de su infracción.

La eficiencia exige que la concesión de la patente sea adecuada, por ejemplo, en cuanto a la exigencia de ausencia de obviedad. De ella dependen tanto los objetivos de la regulación (que valga la pena la protección pese a los costos que tiene), ${ }^{2}$ como la certeza del derecho frente a eventuales nulidades y, sobre todo, al momento de definir si se ha materializado una infracción a los derechos que la patente confiere. Pero también es necesario que la protección que brinda la patente se extienda, en términos razonablemente precisos, a las hipótesis de lo que podría denominarse "fraude a la patente", pues de lo contrario bastaría con que una persona introdujera pequeñas e insignificantes modificaciones a un producto o procedimiento patentado para desactivar y convertir en letra muerta el sistema de protección de los inventos.

Lo anterior resulta plenamente aplicable a la protección penal de la patente, de modo que la interpretación de los tipos penales debe expresar de un modo suficiente y satisfactorio la tensión entre el incentivo al inventor y la difusión universal del conocimiento. El presente estudio tiene por objeto explorar la forma en que el derecho penal puede hacerse cargo de ello en términos compatibles con el principio de legalidad, especialmente desde la perspectiva del mandato de determinación. Con este fin se analiza el derecho comparado

\footnotetext{
${ }^{1}$ Cfr. con abundantes referencias ulteriores LIANOS, Ioannis, "Las implicancias de una teoría regulatoria de la propiedad intelectual (PI) para el derecho de la libre competencia: visión desde Europa”, Trad.: CASTRO, Sebastián, GRUNBERG, Jorge, Revista de Derecho Económico N 75 (2010), pp. 205-283, pp. 221 y ss.

${ }^{2}$ Al respecto véase FERNÁNDEZ, Fernando, "The non-obviousness requirement in the Chilean patent law. A critical assessment”, Revista Chilena de Derecho, Vol. 38, №3 (2011), pp. 487-510.
} 
Polít. crim. Vol. 8, No 15 (Julio 2013), Art. 5, pp. 170 - 209.

[http://www.politicacriminal.cl/Vol_08/n_15/Vol8N15A5.pdf]

sobre interpretación del alcance de las patentes, focalizando dicho análisis en un aspecto específico: en qué medida la protección que brinda la patente y, en consecuencia, la que proporcionan los tipos penales pertinentes, puede extenderse a las denominadas "infracciones no literales". En consecuencia, esta contribución sólo aspira a explicar interpretar los tipos penales del art. 52 de la Ley 19.039 en cuanto al significado de las expresiones "invento patentado" (letra a] del art. 52), "procedimiento patentado" (letra c] del art. 52) e "imiten un invento con solicitud de patente en trámite" (letra d] del art. 52), y además lo hace desde una perspectiva dinámica, pues tal interpretación se realiza al contrastar el invento o procedimiento patentado (o con solicitud de patente en trámite) con un invento o procedimiento presuntamente infractor. ${ }^{3}$

Como contrapartida, el estudio no trata otros aspectos relevantes del lado objetivo del delito de infracción de una patente -como la definición acerca de si es vinculante para el juez penal la decisión administrativa sobre patentabilidad de un objeto ${ }^{4}$, ni del lado subjetivo, como el contenido del dolo en los casos de infracción por equivalencia. ${ }^{5}$

\section{Protección penal de la patente de invención en la Ley 19.039 sobre Propiedad Industrial.}

\subsection{Los tipos penales y las formas de infracción que contemplan.}

El art. 52 de la Ley 19.039 (en adelante, también, "la Ley") sanciona en los términos siguientes la infracción de una patente:

"Serán condenados a pagar una multa a beneficio fiscal de veinticinco a mil unidades tributarias mensuales:

a) Los que maliciosamente fabriquen, utilicen, ofrezcan o introduzcan en el comercio un invento patentado, o lo importen o estén en posesión del mismo, con fines comerciales. Lo anterior se entenderá sin perjuicio de lo dispuesto en el inciso quinto del artículo 49.

b) $(\ldots)^{6}$

\footnotetext{
${ }^{3}$ Para una visión panorámica de los delitos de infracción de una patente en el derecho penal español, bastante similar al chileno en la formulación de los tipos pertinentes, véanse entre otros MARTÍNEZ-BUJÁN, Carlos, Derecho penal económico. Parte especial, $3^{\mathrm{a}}$ ed., Valencia: Tirant lo Blanch, 2011, pp. 162 y ss.; BENEYTEZ, Luis, "Delitos relativos a la propiedad industrial" en: BACIGALUPO, Enrique (dir.), Curso de derecho penal económico, $2^{\mathrm{a}}$ ed., Madrid: Marcial Pons, 2005, pp. 281 y ss. En ellos no se alude, sin embargo, a la doctrina de los equivalentes. En cambio GARCÍA CAVERO, Percy, Derecho penal económico. Parte especial, Lima: Griley, 2007, pp. 164 y ss., ofrece una exhaustiva exposición de las figuras previstas en el derecho peruano, incluyendo el alcance del objeto material de los delitos correspondientes.

${ }^{4}$ Al respecto, aunque con un una argumentación centrada en los signos distintivos, VAN WEEZEL, Alex, "Principio de especialidad de las marcas y delito marcario", Gaceta Jurídica No 315 (2006), pp. 32-38.

5 Sobre el contenido del dolo en general en los delitos de infracción de una patente véanse entre otros CASTIÑEIRA, María Teresa, "El alcance de la protección penal de la propiedad industrial", en: SILVA SÁNCHEZ, Jesús-María, ¿Libertad económica o fraudes punibles? Riesgos penalmente relevantes e irrelevantes en la actividad económico-empresarial, Madrid: Marcial Pons, 2003, p. 280, y GARCÍA CAVERO, Derecho penal económico, cit. nota $n^{\circ} 3$, pp. 198 y ss.

${ }^{6} \mathrm{La}$ letra b) tipifica un delito que no consiste en la infracción de una patente ajena, por lo que no es relevante para esta contribución: “b) Los que, con fines comerciales, usen un objeto no patentado, o cuya patente haya
} 
VAN WEEZEL, Alex. "El delito de infracción de una patente por equivalencia o por imitación".

c) Los que maliciosamente, con fines comerciales, hagan uso de un procedimiento patentado.

d) Los que maliciosamente imiten o hagan uso de un invento con solicitud de patente en trámite, a menos de que, en definitiva, la patente no sea concedida".

Como se puede apreciar, las letras a) y c) sancionan a quien se beneficia de un producto o procedimiento que se considera idéntico al invento patentado, mientras que la letra d) agrega a la modalidad de "hacer uso de un invento" - el mismo- la modalidad de la imitación. Esto significa que el derecho chileno de propiedad industrial conoce básicamente dos formas diversas de infracción punible de una patente: la infracción que consiste en usar o beneficiarse del "mismo" invento patentado o con solicitud de patente en trámite y la infracción que consiste sólo en imitar un invento con solicitud de patente en trámite. La primera de estas formas comprende sin lugar a dudas la denominada infracción literal de la patente, que consiste en la reproducción exacta, como en un espejo, del invento patentado o con solicitud de patente en trámite.

Los problemas surgen cuando la infracción no es burda o literal. Para estos casos, la doctrina y la jurisprudencia han desarrollado una serie de criterios que permiten considerar que el producto o procedimiento cuestionado se encuentra dentro del alcance que se da a la patente al interpretar sus cláusulas, aunque entre ambos existan algunas diferencias. Cuando se cumplen dichos criterios, se habla de una infracción no literal por equivalencia. La infracción no literal por equivalencia se verifica, según se verá a continuación in extenso, cuando en el producto o proceso infractor sólo se sustituyen ciertos elementos o componentes reivindicados en la patente o en la solicitud de patente por otros elementos o componentes que pueden considerarse jurídicamente (sobre la base de un juicio técnico) como equivalentes de los primeros.

En cambio, cuando las diferencias entre el invento patentado y el infractor impiden afirmar que ambos son jurídicamente lo mismo, pero no obstante se trata de productos o procesos muy semejantes, viene a cuento la posibilidad de una infracción no literal por imitación, si se verifican los presupuestos que se analizarán más adelante. A partir de la Ley 19.996 del año 2005, una infracción no literal por imitación sólo puede cometerse cuando se imita el invento cuya solicitud de patente se encuentra en trámite.

Estas diversas modalidades de infracción pueden ordenarse del siguiente modo:

caducado o haya sido anulada, empleando en dicho objeto las indicaciones correspondientes a una patente de invención o simulándolas". 
Polít. crim. Vol. 8, No 15 (Julio 2013), Art. 5, pp. 170 - 209.

[http://www.politicacriminal.cl/Vol_08/n_15/Vol8N15A5.pdf]

\begin{tabular}{c|l|c|c} 
& \multicolumn{2}{|c|}{ el producto o proceso es el mismo } & sólo semejanza \\
\hline $\begin{array}{c}\text { patente } \\
\text { concedida }\end{array}$ & infracción literal & $\begin{array}{c}\text { infracción no } \\
\text { literal por } \\
\text { equivalencia }\end{array}$ & \\
\hline patente en & infracción literal & $\begin{array}{c}\text { infracción no } \\
\text { lrámite }\end{array}$ & $\begin{array}{c}\text { infracción no } \\
\text { literal por } \\
\text { imitación }\end{array}$
\end{tabular}

Tanto para afirmar que el producto o procedimiento cuestionado se encuentra dentro del alcance que se da a la patente al interpretar sus cláusulas (infracción por equivalencia), como para sostener que ese producto o procedimiento puede considerarse una imitación de otro con solicitud de patente en trámite, es necesario aceptar que la protección de la patente se extiende más allá de lo que prima facie comprende la estricta literalidad de las reivindicaciones. El conjunto de los presupuestos bajo los cuales tal extensión resulta aceptable -positivamente en caso de equivalencia y negativamente en caso de imitación- se conoce como "doctrina de los equivalentes". La doctrina de los equivalentes es la forma en que se operacionaliza jurídicamente, al interpretar la patente en caso de conflicto, la tensión entre el incentivo al inventor y la difusión universal del conocimiento. Los efectos que ello produce en la interpretación de los tipos penales son los que deben contrastarse con el mandato de determinación. ${ }^{7}$

\footnotetext{
${ }^{7}$ La aceptación de la teoría de los equivalentes en el ámbito penal no es problemática en el ordenamiento jurídico chileno, que incluso acepta una infracción no literal y punible por imitación. Tampoco lo ha sido en el derecho alemán, donde, igual que en la mayor parte de los ordenamientos, no hay duda que la infracción punible comprende igualmente los casos de equivalencia: cfr. NENTWIG, Malte, en: ACHENBACH, Hans y RANSIEK, Andreas (editores), Handbuch Wirtschaftsstrafrecht, $3^{\text {a }}$. ed., Heidelberg et al.: C.F. Müller, 2011, pp. 1335 y ss.; en el mismo sentido TIEDEMANN, Klaus, Wirtschaftsstrafrecht. Besonderer Teil, $2^{\mathrm{a}}$ ed., Köln-München: Carl Heymanns Verlag, 2008, p. 233, quien además alude a los problemas de error sobre la existencia y alcance de la patente que pueden producirse en los casos de infracción por equivalencia. En el derecho español, se acepta sin problemas -aunque sin mayor desarrollo teórico- la infracción punible por equivalencia ya desde principios del siglo XX (cfr. MASCAREÑAS, C.E., Los delitos contra la propiedad industrial, $2^{\mathrm{a}}$ ed., Barcelona: Librería Bosch, 1960, p. 98: "No es necesario, tampoco, que sea una reproducción exacta del objeto de la patente. Basta que se reproduzca lo esencial, aunque se introduzcan modificaciones que no afecten a la esencialidad. Es, por tanto, irrelevante el que se modifiquen elementos accesorio o secundarios"; a continuación se citan fallos del Tribunal Supremo desde el año 1910); esta situación se mantiene hasta hoy en los comentarios y manuales al uso: véase por ejemplo GONZÁLEZ RUS, Juan, Delitos contra el patrimonio y contra el orden socioeconómico (VIII). Delitos relativos a la propiedad intelectual e industrial, al mercado y a los consumidores, en COBO DEL ROSAL, Manuel (coord.), Derecho penal español. Parte especial, $2^{\mathrm{a}}$ ed., Madrid: Dykinson, 2005, pp. 569 y ss.; igualmente SEGURA GARCÍA, María, "La protección penal de los derechos integrantes de la propiedad industrial", Cuadernos de Derecho Judicial $\mathrm{N}^{\circ} 10$ (1998), pp. 13 y ss. (en especial nota 74: el derecho penal español acoge la doctrina de los equivalentes - que la autora considera de origen alemán- cuyo contenido se recoge en la Sentencia del Tribunal Supremo de 10 de junio de 1968: "En la protección de cualquier invento registral se entenderán comprendidas todas la variantes de forma, materia, tamaño, disposición de elementos e incluso la toda sustitución de esos elementos por otros, cuando con ello no se altere el principio fundamental de la invención descrita, reivindicada y amparada por la patente o modelo de utilidad preexistente en el registro"). Respecto del derecho peruano, en cambio, GARCÍA CAVERO, Derecho penal económico, cit. nota n 3, p. 187, afirma
} 
Lo anterior supone un doble desafío. Por una parte, la aplicación ha de realizarse principalmente a la luz de la experiencia observada en otros ordenamientos jurídicos, pues la evolución de la materia en el derecho comparado es el contexto del que han surgido tanto la escasa praxis como la regulación chilenas. Por otro lado, la doctrina de los equivalentes es expresión de un modelo interpretativo marcadamente teleológico. Esto hace que en la interpretación de los tipos penales pertinentes se superpongan dos planos valorativamente complejos. En primer lugar está la afirmación (o negación) de la equivalencia como resolución de la tensión entre incentivo al inventor y difusión del conocimiento $\mathrm{y}$, en segundo término, el ejercicio propiamente dogmático de interpretación de elementos normativos de alta densidad que ostentan, por lo mismo, un compromiso accesorio particularmente intenso. ${ }^{8}$

\subsection{Conceptos relevantes.}

Las reivindicaciones o cláusulas definen el objeto para el que se solicita la protección de la patente. Según la Ley 19.039, deben ser claras y concisas y han de fundarse en la memoria descriptiva (art. 43 bis inciso $2^{\circ}$ de la Ley). La memoria descriptiva es, según el Reglamento de la Ley sobre Propiedad Industrial (Decreto Supremo 236/2005, art. $2^{\circ}$; en adelante también "el Reglamento"), el documento mediante el cual el solicitante da a conocer en forma clara y detallada su invención, modelo de utilidad, dibujo o diseño industrial, esquema de trazado o topografía de circuitos integrados y, además, el estado de la técnica relacionado con ellos. El estado de la técnica -también según el art. $2^{\circ}$ del Reglamento- es aquel conocimiento que ha sido colocado al alcance del público en cualquier parte del mundo, aunque sea totalmente desconocido en Chile, mediante una publicación, la venta o comercialización, el uso o cualquier otro medio, antes de la fecha de presentación de una solicitud o de la reivindicación de la prioridad de un derecho de propiedad industrial en Chile.

La precisión de las reivindicaciones es muy importante, pues el alcance de la protección otorgada por la patente o la solicitud de patente se determina por el contenido de las reivindicaciones, mientras que la memoria descriptiva y los dibujos "sólo sirven para interpretar las reivindicaciones" (art. 49 inciso $3^{\circ}$ de la Ley). Para facilitar la precisión, las reivindicaciones enuncian y delimitan el objeto comprendido en la patente siguiendo la estructura formal establecida en el Reglamento: número, preámbulo, la expresión

que la protección penal asociada a la patente, a diferencia de la protección respecto de lo similar que se concede respecto de las marcas, no abarcaría "la utilización de una solución equivalente a la invención patentada que solamente cambia aspectos inesenciales de la invención".

${ }^{8}$ Sobre el problema de la accesoriedad del derecho penal en general HOHMANN, Olaf, "Gedanken zur Akzessorietät des Strafrechts", Zeitschrift für internationale Strafrechtsdogmatik, 1/2007, pp. 38 y ss.; recientemente también ROJAS, Luis, "Accesoriedad del derecho penal”, en: VAN WEEZEL, Alex, (editor), Humanizar y renovar el derecho penal. Estudios en memoria de Enrique Cury, Santiago: Legal Publishing, 2013, pp. 93-107. En particular sobre los problemas de accesoriedad administrativa -en este caso, respecto de la resolución que concede la patente- y sus efectos en la determinación de los tipos, fundamental (aunque discutible en su conclusión: la resolución es constitutiva de la tipicidad) TIEDEMANN, Klaus, Tatbestandsfunktionen im Nebenstrafrecht, Tübingen: Mohr Siebeck, 1969, pp. 272 y ss.; sobre los demás problemas que plantea la accesoriedad en el derecho penal de la propiedad industrial véase GARCÍA CAVERO, Derecho penal económico, cit. nota n 3, pp. 172-175. 
Polít. crim. Vol. 8, No 15 (Julio 2013), Art. 5, pp. 170 - 209.

[http://www.politicacriminal.cl/Vol_08/n_15/Vol8N15A5.pdf]

“caracterizado", y la caracterización propiamente tal. ${ }^{9}$ Las reivindicaciones pueden ser a su vez independientes - cuando designan el objeto de la invención y sus características principales- o dependientes, cuando contienen las características de otra reivindicación y precisan los detalles o alternativas adicionales para las que se solicita la protección de la patente.

De particular interés para las consideraciones que siguen es la noción de equivalente técnico. Conforme al art. $2^{\circ}$ del Reglamento, es el "elemento o medio que realiza la misma función que aquel que está reivindicado en una invención, de la misma manera y produciendo el mismo efecto o resultado señalado en la reivindicación". ${ }^{10}$

\section{La doctrina de los equivalentes.}

\subsection{El problema.}

En los países que, como Chile, han adoptado el sistema de reivindicaciones con el fin de determinar con la mayor precisión posible el objeto de protección de las patentes, suele producirse el problema de que el tenor literal de la reivindicación no cubre plenamente el objeto protegible desde el punto de vista de la razón de ser de la protección. Esto ocurre por diversas razones. Puede ser, por ejemplo, que no se hayan desarrollado aún las expresiones lingüísticas capaces de reflejar cabalmente la novedad de la invención, por lo que es necesario servirse de denominaciones que se refieren a invenciones anteriores, pero que permiten entender de qué se está hablando. También ocurre que el inventor, al patentar su invención, no está en condiciones de prever todas las posibles variantes que pueden introducirse en el futuro, algunas de las cuales podrían resultar muy semejantes al invento patentado.

Una interpretación literalista de las reivindicaciones debilitaría sustancialmente la protección e incentivos asociados a la patente, pues para burlar esa protección y con el fin de aprovecharse ilegítimamente de una invención ajena, bastaría con introducir en un invento modificaciones insustanciales e irrelevantes. Este peligro se aprecia aun con mayor claridad si se tiene en cuenta que los inventores no pueden redactar las reivindicaciones en términos muy amplios o generales, pues en tal caso el Instituto Nacional de Propiedad Industrial ("INAPI") -la oficina administrativa encargada de la concesión de patentes- los obligará a restringir el tenor literal como condición para el otorgamiento de la patente.

Por otro lado, sin embargo, las reivindicaciones definen por exclusión todo lo que no se encuentra protegido por ellas, y por lo tanto puede ser libremente explotado y utilizado por otras personas. Cuanto más clara y exacta sea una reivindicación, más precisa será la

\footnotetext{
9 "La caracterización es la parte medular de una cláusula por cuanto define los elementos, combinaciones o agrupaciones de ellos, que se constituyen en el aporte técnico que reúne las condiciones de aplicación industrial, novedad y nivel inventivo, y por lo tanto el mérito para otorgar una patente. Estos elementos deben estar necesariamente en cada una de las reivindicaciones, dejando la primera para reconstruir la invención y las reivindicaciones dependientes para especificar dichos elementos" (art. 43 inciso $3^{\circ}$ del Reglamento, cursivas añadidas).

${ }^{10}$ La norma reproduce la definición del antiguo Reglamento, contenido en el Decreto Supremo 177/1991.
} 
VAN WEEZEL, Alex. "El delito de infracción de una patente por equivalencia o por imitación”.

información que ella proporcionará a los terceros acerca de qué es lo que se encuentra protegido por la patente y qué, en cambio, queda al margen de esa protección. De allí que el problema con el que se encuentra el intérprete de una patente pueda caracterizarse en los siguientes términos: cómo evitar el literalismo en la interpretación con el fin de proteger e incentivar al titular de la patente, pero al mismo tiempo sin otorgar a éste un monopolio sobre aquello que no solicitó en forma oportuna, o sobre aquello que es parte del arte previo y que, por lo tanto, nadie se puede apropiar. Los esfuerzos por explicar y resolver este conflicto han dado origen a la doctrina de los equivalentes, que se ha desarrollado especialmente en los Estados Unidos de Norteamérica, Japón, Alemania y Gran Bretaña, con diversos matices y énfasis.

\subsection{Antecedentes de la doctrina de los equivalentes en Chile y en el derecho comparado.}

Aunque sólo obtuvo reconocimiento positivo expreso en 1991, la doctrina de los equivalentes es conocida y aplicada en Chile desde antiguo en el contexto de los procedimientos por supuesta infracción de una patente. Ya en un estudio de 1945, referido a las figuras contempladas en los arts. 19 y 21 de la antigua ley sobre propiedad industrial, cuyo texto refundido se había establecido por Decreto Supremo de Fomento No 958, de 8 de junio de 1931, se afirmaba sin dudas de ningún tipo:

"Tampoco es inconveniente para que exista este delito el que haya diferencias entre el producto patentado y el que no lo está, en la materia, la forma, la dimensión o de otro orden, a menos que en ellas precisamente radique la novedad, originalidad y mayor utilidad del invento". ${ }^{11}$

En época más cercana, un fallo de 1986 hace referencia a la doctrina civilista de comienzos del siglo XX, que ya se hacía cargo del problema y sostenía claramente que, para cometer el delito sancionado en el art. 19 de la antigua ley, no es necesario que "la invención descrita en la patente sea reproducida idénticamente, pues ciertas diferencias de detalle no son a menudo sino el medio de disfrazar la explotación ilícita y no impiden que se consume

\footnotetext{
${ }^{11}$ RAYO, Jorge, Delitos contra la propiedad industrial, Tesis de Licenciatura, Universidad de Chile, 1945 , p. 60. La tesis se mueve en el ámbito de lo que venía siendo opinión común en la doctrina y jurisprudencia españolas, que sirven de referente al autor. Por ejemplo, pocos años antes el Tribunal Supremo español había dictaminado lo siguiente: "Declarándose probado por el tribunal de instancia que el condenado con pleno conocimiento de que el industrial L tenía inscrita y registrada en el Registro de la Propiedad Industrial una patente de invención denominada $\mathrm{N}$ con un nuevo sistema de refuerzos para sommier, de las características que se señalan, le fueron encontrados en su establecimiento diez sommiers por él fabricados, y dispuestos para la venta con refuerzos metálicos, los cuales respondían a un mismo e idéntico sistema de suspensión que el patentado $\mathrm{N}$ e incluidos ambos en las reivindicaciones de la patente registrada en su parte esencial y fundamental, aunque el no patentado fuera inferior al $\mathrm{N}$ en dos grados de estabilidad debido a la simple $\mathrm{y}$ accidental modificación de sus secundarios elementos y (...) es notorio que el condenado atentó a los derechos nacidos de la concesión y cometió el delito de usurpación de patente (...) sin que sea óbice, al efecto, el que no copiara exactamente el sistema patentado, si utilizaba su procedimiento" (sentencia de 9 de diciembre de 1941, citada por MASCAREÑAS, Los delitos contra la propiedad industrial, cit. nota $\mathrm{n}^{\mathrm{o}} 7$, $\mathrm{p}$. 99; las cursivas provienen posiblemente de la cita y no del original).
} 
Polít. crim. Vol. 8, No 15 (Julio 2013), Art. 5, pp. 170 - 209.

[http://www.politicacriminal.cl/Vol_08/n_15/Vol8N15A5.pdf]

la usurpación de la idea esencial del procedimiento patentado; y, por lo tanto, se cometa el delito". ${ }^{12}$

Este último antecedente sugiere que el derecho de patentes chileno se encuentra en línea con el "fundamento de equidad" asociado a la teoría de los equivalentes en parte de la jurisprudencia comparada; es decir, podría haber buenas razones para pensar que se la concibe como un dispositivo contra el denominado "fraude a la patente", según se verá a continuación.

\subsubsection{Graver Tank y Warner-Jenkinson en los Estados Unidos.}

La doctrina de los equivalentes se conoce en los Estados Unidos desde el siglo XIX y es probablemente en este país donde ha experimentado su mayor desarrollo, aun sin un reconocimiento legislativo o estatutario contundente. Los casos considerados fundamentales para el establecimiento de la doctrina son sin lugar a dudas los fallos de la Corte Suprema en Graver Tank v. Linde Air Products Co., 339 U.S. 605 (1950), y WarnerJenkinson Company v. Hilton Davis Chemical Co., 520 U.S. 17 (1997).

En Graver Tank, la patente consistía en una pasta de soldadura con una determinada composición química, y el producto infractor, en una pasta de soldadura con idéntica composición, salvo por la sustitución de manganeso por magnesio. La Corte Suprema consideró que existía equivalencia, pues para un químico metalúrgico ambos elementos presentaban reacciones similares en su aplicación a una pasta de soldadura. En términos más generales, la Corte sienta en Graver Tank el criterio de que la doctrina de los equivalentes es necesaria para no incentivar la piratería que se comete mediante un verdadero "fraude a la patente", es decir, aquella donde el infractor realiza pequeñas modificaciones al invento patentado con el fin de burlar la protección. Por otro lado, aunque reconoce que el test apropiado para saber si existe equivalencia consiste en comprobar una "triple identidad" en lo sustancial -los artefactos deben realizar sustancialmente la misma función de sustancialmente la misma manera, alcanzando un resultado sustancialmente idéntico-, señala en términos enfáticos que el análisis de la equivalencia no es algo mecánico, sino que debe hacerse ponderando el contexto de la patente, el arte previo y las circunstancias particulares del caso. Por eso se suele decir que Graver Tank establece la doctrina de los equivalentes como una forma de equity, es decir, como una forma de justicia en el caso particular. ${ }^{13}$

En Warner-Jenkinson, por su parte, la Corte Suprema reafirmó la vigencia de la doctrina de los equivalentes, pero estableció con mayor énfasis tanto la necesidad de aplicar la denominada all limitations rule - un criterio que obliga a comprobar la equivalencia sin

\footnotetext{
${ }^{12}$ La cita, realizada por la Corte de Apelaciones de San Miguel en sentencia de 6.X.1986 (y suscrita por los ministros Humberto Espejo Zúñiga, Sergio Urrejola Rozas y Fernando Fueyo Laneri), está tomada de CLARO SOLAR, Luis, Explicaciones de Derecho Civil Chileno y Comparado, Tomo Sexto, De los bienes, Santiago, 1930, p. 617. Sobre la recepción posterior de la doctrina en Chile véase MELOSSI, Andrés, "Interpretación de las patentes de invención. Doctrina de los equivalentes y su aplicación en Chile", en: MORALES, Marcos (coord.), Temas actuales de propiedad intelectual. Estudios en homenaje a la memoria del profesor Santiago Larraguibel Zavala, 2a ed. Santiago: Abeledo Perrot, 2007, pp. 199-237, pp. 230 y ss.

${ }^{13}$ American Jurisprudence (Thomson West, $2^{\mathrm{a}}$ ed.), Vol. 27, voz Equity, § 1.
} 
VAN WEEZEL, Alex. "El delito de infracción de una patente por equivalencia o por imitación".

considerar el invento como un todo, sino parte por parte-, como el estoppel de la historia administrativa de concesión de la patente. ${ }^{14} \mathrm{~A}$ estos criterios limitativos nos referiremos enseguida. El caso decía relación con un proceso de "ultrafiltración" para la purificación de tinturas, que consideraba un cierto tipo de filtro operando a un cierto nivel de $\mathrm{pH}$. Según la patente, el filtro operaba a un $\mathrm{pH}$ de entre 9 y aproximadamente 6 , mientras que el producto infractor, idéntico en todo lo demás, operaba a un $\mathrm{pH}$ de 5 . La Corte estimó que un $\mathrm{pH} 5$ quedaba cubierto por la expresión "aproximadamente 6" y por lo tanto se trataba de un equivalente.

A partir de estos casos se ha ido formando la doctrina de los equivalentes en los Estados Unidos. La doctrina de ambos se encuentra vigente hasta hoy, en sus aspectos fundamentales.

\subsubsection{La influencia del derecho comunitario en Alemania.}

La doctrina de los equivalentes se aplica también desde hace tiempo en Alemania, aunque el derecho de la Unión Europea ha venido a darle un nuevo impulso, pues obliga a "considerar en la determinación del ámbito de protección de una patente aquellos elementos que son equivalentes a los que se mencionan en las reivindicaciones" (Revisión del Tratado Europeo sobre Patentes, Munich 29.XI.2000).

Entre los fallos del Tribunal Federal alemán relativos a la doctrina de los equivalentes destaca el que recayó en el caso denominado Pipeline (Mitt. 2002, 228). ${ }^{15}$ En esta sentencia, el tribunal establece que existirá equivalencia cuando:

- el artefacto que se aparta de la literalidad de la reivindicación resuelve el problema que dio lugar a la invención sirviéndose de medios que surten los mismos efectos;

- el especialista podía encontrar, gracias a sus conocimientos especializados, esos medios que surten los mismos efectos;

- el especialista basa hasta tal punto sus consideraciones anteriores en el sentido de la reivindicación, que él mismo, conociendo ese sentido, pudo considerar los medios diversos que usa el aparato modificado como medios equivalentes para realización de ese sentido.

\subsubsection{La interpretación según el propósito o finalidad en el Reino Unido.}

También en el Reino Unido se conoce una forma de equivalencia, en cuanto los jueces deben analizar la finalidad o propósito (una especie de interpretación teleológica) de las reivindicaciones o, más precisamente, de las diferencias existentes entre la patente y el supuesto infractor. Más allá de los diversos acentos que es posible encontrar en los precedentes, es claro que en el Reino Unido no procede interpretar las reivindicaciones en forma literal.

\footnotetext{
${ }^{14}$ Cfr. infra 3.4.2, y American Jurisprudence, cit. nota n ${ }^{\circ} 13$, Vol. 28. voz Estoppel and Waiver $\S 1$.

${ }^{15}$ Véase al respecto NENTWIG, Handbuch Wirtschaftsstrafrecht, cit. nota ${ }^{\circ} 7$, p. 1336.
} 
Polít. crim. Vol. 8, No 15 (Julio 2013), Art. 5, pp. 170 - 209.

[http://www.politicacriminal.cl/Vol_08/n_15/Vol8N15A5.pdf]

Uno de los casos en que se desarrolla con mayor detalle el problema de la equivalencia, y cuya doctrina ha sido en lo sustancial sucesivamente confirmada, es el caso Improver Corp. v. Remington Consumer Products Ltd., (1989) R.P.C. 69 (U.K. Court of Appeal per Dillon L.J.). En Improver, el test de equivalencia conforme al análisis del propósito o finalidad es -en una traducción libre- el siguiente:

- ¿tiene la variante un efecto esencial sobre el modo en que trabaja la invención? Si es así, la variante no queda comprendida por la reivindicación. Si no,

- ¿podría esta variante sin efecto esencial haber sido obvia a la fecha de publicación de la patente para un lector versado en el campo técnico pertinente? Si no es así, la variante está fuera de la reivindicación. Si la respuesta es afirmativa,

- ¿podía el lector versado en el campo técnico correspondiente, a pesar de lo anterior, desprender del lenguaje de la reivindicación que el titular de la patente tuvo la intención de que el cumplimiento estricto de su significado literal constituyera un requisito esencial de la invención? Si la respuesta es afirmativa, entonces la variante está fuera de la reivindicación.

\subsubsection{La versión restrictiva de la doctrina de los equivalentes en Japón.}

Aunque en Japón prima un criterio mucho más restrictivo en la protección de los inventos patentados, la Corte Suprema japonesa ha reconocido también la doctrina de los equivalentes. ${ }^{16}$ El caso Ball Spline (1998) establece al respecto cinco parámetros, análogos a los que considera el Tribunal Federal alemán, y a los tests y límites desarrollados por la Corte de Apelaciones para el Circuito Federal de los Estados Unidos. ${ }^{17}$ Los dos primeros parámetros son:

- test sobre el elemento no esencial (non-essential element test): los elementos, partes o componentes respecto de los cuales existan diferencias entre la invención patentada y el producto objetado no deben ser elementos, partes o componentes esenciales o sustanciales de la invención patentada. Es decir, sólo los elementos no esenciales pueden ser reemplazados con equivalentes;

- test sobre la capacidad de reemplazo (capability of replacement test): el objeto protegible de la invención patentada debe estar en condiciones de ejecutarse y de obtener los mismos efectos y resultados cuando los elementos o componentes

\footnotetext{
${ }^{16}$ Cfr. SONODA \& KOBAYASHI, "Doctrine of Equivalents in Japan after Supreme Court Decision in 1998 in Ball Spline Bearing Case 2(1999)", disponible en http://www.patents.jp/Archive/19980415-04.pdf [visitado el 05.03.2012]; y TOSHIKO TAKENAKA, "The Doctrine of Equivalents in Japan", 6 CASRIP Publication Series: Rethinking International Intellectual Property 125 (2000), disponible en http://www.law.washington. edu/casrip/symposium/Number6/Takenaka.pdf [visitado el 05.03.2012].

${ }^{17}$ THK v. Tsubakimoto ("Ball Spline Bearing Case"), 1994 (O) No. 1083 (Sup. Ct., Feb. 24, 1998), texto en inglés disponible en http://www.courts.go.jp/english/judgments/text/1998.02.24-1994-O-No.1083.html [visitado el 05.03.2012]. Por regla general, cada circuito judicial en los Estados Unidos tiene su propia Corte de Apelaciones. Sin embargo, en materia de propiedad intelectual existe una sola Corte de Apelaciones para todo el país, conocida precisamente como Circuito Federal.
} 
VAN WEEZEL, Alex. "El delito de infracción de una patente por equivalencia o por imitación".

adicionales sean sustituidos por los elementos o componentes pertenecientes al producto acusado de infracción.

Los otros tres parámetros de Ball Spline constituyen en realidad limitaciones a la doctrina de los equivalentes. Nos referiremos brevemente a ellas en el apartado subsiguiente: obviedad, estado del arte o de la técnica, e historia del otorgamiento de la patente.

\subsection{Efectos de la aplicación de la doctrina de los equivalentes.}

No obstante las diferencias de detalle que presenta la doctrina de los equivalentes en las diversas jurisdicciones, el denominador común consiste en que aplicarla implica afirmar que existe una identidad entre el invento patentado y su equivalente. Quien afirma la equivalencia, declara que no hay base jurídica para tratar al equivalente como si no fuera idéntico al invento patentado. Es decir, cuando se aplica la doctrina de los equivalentes se asume que el producto o proceso acusado de infracción es lo mismo que el producto o proceso patentado, y no solamente algo similar o parecido, como sucedería en el caso de la imitación de un invento con solicitud en trámite. Dicho de otro modo, al aplicar la doctrina, la respectiva reivindicación toma la forma de "x y sus equivalentes" (Winans v. Adam, 56 U.S. 330 [1854]).

En Union Paper-Bag Machine Co. v. Murphy, 97 U.S. 120 (1878), que fue uno de los antecedentes importantes de Graver Tank, se expresa lo anterior de la siguiente forma:

"El equivalente sustancial de una cosa, en el sentido del derecho de patentes, es lo mismo que esa cosa; de tal manera que si dos artefactos realizan el mismo trabajo de sustancialmente el mismo modo, y alcanzan así sustancialmente el mismo resultado, ambos son lo mismo, aunque se diferencien en el nombre, la forma o la apariencia".

En el fallo recaído en el caso Warner-Jenkinson, que recoge la cita anterior, se formula esta idea en términos aun más generales: "Si el predicado esencial de la doctrina de los equivalentes es la noción de identidad entre una invención patentada y su equivalente, no existe base alguna para tratar a un equivalente infractor de un modo distinto que a un artefacto que infringe los términos expresos de una patente. La aplicación de la doctrina de los equivalentes es, por lo tanto, similar a la determinación de la infracción literal". Refiriéndose a un aspecto distinto, pero relacionado, el fallo agrega que, por consiguiente, la aplicación de la doctrina tampoco requiere la prueba de algún elemento intencional o subjetivo. $^{18}$

\subsection{Límites a la doctrina de los equivalentes, en particular en los Estados Unidos.}

Los límites a la doctrina de los equivalentes tienen por objeto impedir que la extensión de la protección que resulta de la equivalencia conduzca a una pérdida intolerable de certeza en cuanto a la cobertura de la patente, o bien, que permita al titular arrogarse derechos exclusivos sobre un objeto que no se le ha concedido. Entre los límites más desarrollados

${ }^{18}$ KIEFF, F. Scott et al., Principles of patent law: Cases and Materials, $4^{\mathrm{a}}$ ed., New York: Thomson West, 2008, p. 929. 
Polít. crim. Vol. 8, No 15 (Julio 2013), Art. 5, pp. 170 - 209.

[http://www.politicacriminal.cl/Vol_08/n_15/Vol8N15A5.pdf]

en la jurisprudencia ${ }^{19}$ destacan la regla de la totalidad de las limitaciones o elementos, el estoppel de la historia de la tramitación, la doctrina de la revelación al público y el arte previo. $^{20}$

\subsubsection{La regla de la totalidad de las limitaciones o elementos.}

Hay dos formas de interpretar el alcance de una patente para determinar si una variante la infringe desde el punto de vista de la doctrina de los equivalentes. La primera posibilidad consiste -básicamente- en atender al invento como un todo, en una consideración global, mientras que la otra alternativa obliga a hacerse cargo de las diferentes partes o elementos de la reivindicación y de la variante supuestamente infractora, de tal manera que "el demandante debe demostrar la presencia de cada elemento [reivindicado] o de su equivalente sustancial en el aparato acusado de infracción". ${ }^{21}$ Como se vio, al menos a partir de Warner-Jenkinson es absolutamente predominante en los Estados Unidos esta última alternativa, denominada all elements rule o bien all limitations rule, y que aquí traduciremos como "regla de la totalidad de los elementos o limitaciones".

Conforme a esta regla, y siguiendo de cerca el razonamiento de Warner-Jenkinson, cada elemento contenido en una reivindicación se considera sustancial para definir el ámbito de la invención protegida. Por lo tanto, la doctrina de los equivalentes debe aplicarse a los elementos individuales de la reivindicación, y no a la invención tomada en su conjunto. Al mismo tiempo, es clave asegurar que la aplicación de la doctrina, incluso cuando se realiza respecto de cada elemento, no se lleve tan lejos que conduzca a eliminar totalmente un elemento reivindicado. El tribunal manifiesta en los siguientes términos la preocupación que le llevó a introducir este límite: "En la medida en que la doctrina de los equivalentes no se extienda más allá de los límites descritos (...) confiamos en que ella no vaciará las funciones centrales que están llamadas a cumplir las reivindicaciones". ${ }^{22}$

\footnotetext{
${ }^{19}$ Para una sintética visión de conjunto, véase ADELMAN, Martin J. et al., Cases and materials on patent law, $3^{\mathrm{a}}$ ed., St. Paul (Minnesota): Thomson West, 2009, pp. 714 y ss.

${ }^{20}$ La doctrina de los equivalentes es parte del proceso de interpretación de las reivindicaciones de una patente, y por lo tanto su aplicación se realiza en armonía con los demás criterios de interpretación, que por su parte contienen limitaciones adicionales. En Chile, la ley dispone que sólo se interpretan las reivindicaciones (art. 49 inciso $3^{\circ}$ de la Ley), de modo que la memoria de descriptiva sólo puede cumplir una función auxiliar. En el derecho comparado, entre los principales criterios de interpretación asentados se encuentran los siguientes: las reivindicaciones deben interpretarse primero en el contexto de la misma invención (Autogiro Co. of America v. United States, 384 F.2d 391 [Ct. Cl. 1967]); la evidencia extrínseca no puede contradecir o variar los términos explícitos de las reivindicaciones (Vitronics Corp. v. Conceptronic Inc., 90 F.3d 1576 [Fed. Cir. 1996]); al determinar el alcance o cobertura de una reivindicación no es lícito incorporar en ella por vía interpretativa las limitaciones de otra reivindicación, especialmente desde una reivindicación dependiente hacia una independiente (cfr. ente otros Karlin Tech., Inc. v. Surgical Dynamics, Inc., 177 F.3d 968 [Fed. Cir. 1999]).

${ }^{21}$ Esta es la clásica formulación acuñada en el caso Pennwalt Corp. v. Durand-Wayland, Inc., 833 F.2d 931 (Fed. Cir. 1987) (en banc).

${ }^{22}$ Cfr. MOORE, Kimberly et al., Patent Litigation and Strategy, $3^{a}$ ed., St. Paul (Minnesota): Thomson West, 2008, pp. 432 y ss.; cfr. también HOEKMAN, Doneil John, Modern Judicial Interpretations of U.S. Patent Law, Santa Clara (California): Documech, 2009, p. 20.
} 
VAN WEEZEL, Alex. "El delito de infracción de una patente por equivalencia o por imitación".

Sobre esta base, se han desarrollado dos corrientes muy pronunciadas en la aplicación de la regla de la totalidad de los elementos. Por una parte, se puede sostener que para afirmar la equivalencia debe existir una especie de "triple identidad": en cuanto a la función que cumple el elemento, la forma en que la cumple y el resultado obtenido por él. Por otra, cabe determinar la equivalencia o inequivalencia atendiendo a si las diferencias son "insustanciales" o no lo son, especialmente en el caso de inventos que no consisten en máquinas o dispositivos mecánicos. Sin embargo, tal como señala el fallo de la Corte Suprema en Warner Jenkinson, hoy "parece existir acuerdo en que mientras la triple identidad es apropiada para el análisis de aparatos mecánicos, ella proporciona un marco muy pobre para el análisis de otros productos o de procedimientos". ${ }^{23}$

Pero hay sobre todo dos aspectos que inciden en que la jurisprudencia se haya inclinado en la práctica por el criterio de la sustancialidad de las diferencias. Ambos se analizarán en los apartados siguientes: (a) la posibilidad de manipular la descripción que los potenciales infractores realizan de sus productos o procesos (agrupación o desagregación de elementos), y (b) lo que se ha denominado como "inconsistencia insalvable" de la regla de la totalidad de los elementos o limitaciones. A continuación (c), se hará referencia también a Corning Glass Works v. Sumitomo Electric USA, Inc., 868 F.2d 1251 (Fed. Cir. 1989), un fallo del Circuito Federal que muestra de un modo particularmente gráfico el juego entre la doctrina de los equivalentes y la regla o limitación de la totalidad de los elementos.

\section{a) Manipulabilidad o aleatoriedad de las descripciones.}

En especial a partir de Warner-Jenkinson se impuso el criterio según el cual el concepto de equivalencia nunca puede llevar a vaciar o eliminar del todo un elemento contemplado en una reivindicación. Si esto ocurriera, entonces habría que negar la equivalencia por aplicación de la regla de la totalidad de los elementos. Sin embargo, es fácil advertir que, si se aplicara a ultranza este criterio, todo podría depender de la forma como casualmente quedó construida una reivindicación, por un lado, o de la forma como el acusado de infracción describe estratégicamente su variante, por otro.

Para ilustrarlo en términos sencillos, se puede considerar una tabaquera con seis lados. ${ }^{24}$ La reivindicación podría ser: (i) "una tabaquera consistente en un primer lado, un segundo lado, un tercer lado, un cuarto lado, un quinto lado y un sexto lado", o bien (ii) "una tabaquera de seis lados". Las dos reivindicaciones definen exactamente el mismo objeto literal ¿Resultaría infringida la patente por una tabaquera de cinco lados bajo la regla de la totalidad de los elementos? Si se aplica esta regla de un modo rígido, excluiría la infracción en el caso de la primera formulación de la reivindicación porque "faltaría" un elemento consistente en un lado. Por el contrario, muy probablemente se admitiría una infracción por equivalencia de la segunda formulación, si se puede demostrar que cinco lados son, en el caso de este invento, sustancialmente lo mismo que seis. Por lo tanto, es posible burlar el

\footnotetext{
${ }^{23}$ Cfr. ADELMAN, Patent Law, cit. nota ${ }^{\circ} 19$, p. 711.

${ }^{24}$ El ejemplo está tomado de KIEFF, Principles of patent law, cit. nota ${ }^{\circ} 18$, p. 934.
} 
Polít. crim. Vol. 8, No 15 (Julio 2013), Art. 5, pp. 170 - 209.

[http://www.politicacriminal.cl/Vol_08/n_15/Vol8N15A5.pdf]

control de la regla de la totalidad de las limitaciones por la vía de reducir el número de elementos o de agruparlos en el producto infractor. ${ }^{25}$

En esta misma línea, cabe preguntarse si se puede entender "vaciado" un elemento cuando el producto supuestamente infractor tiene un solo elemento que realiza la misma función que dos elementos contenidos en la reivindicación; o, a la inversa, cuando el artefacto supuestamente infractor tiene dos elementos que realizan la misma función que un solo elemento según la reivindicación. En el caso Eagle Comtronics, Inc. v. Arrow Communication Laboratories Inc., la Corte de Apelaciones del Circuito Federal se refirió precisamente a estas cuestiones:

"Aunque ningún elemento de la reivindicación puede faltar totalmente en el aparato supuestamente infractor, para determinar si se ha producido el vaciamiento o la eliminación total de un elemento es preciso tener en cuenta lo siguiente: cuando dos elementos del aparato supuestamente infractor realizan una única función de la invención patentada; o cuando elementos diversos de una reivindicación se combinan para constituir un solo elemento en el aparato supuestamente infractor, no necesariamente se ha producido el vaciamiento o eliminación de un elemento, y la doctrina de los equivalentes puede tener aplicación si las diferencias son insustanciales". ${ }^{26}$

En su jurisprudencia más reciente, el Circuito Federal ha señalado que para determinar si la apreciación de una infracción según la doctrina de los equivalentes llevaría a eliminar una limitación de la reivindicación (lo cual está prohibido según la regla de la totalidad de los elementos), los tribunales deben considerar la "totalidad de las circunstancias del caso", evaluando "si el equivalente invocado podría ser caracterizado sin problemas como un cambio insustancial en la materia reivindicada sin dejar desprovista de significado a la limitación pertinente". 27

b) La denominada "inconsistencia insalvable" de la regla.

El Circuito Federal y la doctrina advirtieron, al menos desde mediados de los años 90 del siglo pasado, que la regla de la totalidad de los elementos adolece de una inconsistencia interna imposible de subsanar. Por una parte, la teoría de los equivalentes se aplica en orden

\footnotetext{
${ }^{25}$ Una situación similar se produce cuando se trata de un tenedor con cuatro dientes. La reivindicación podría ser: (a) "un tenedor compuesto de un mango cilíndrico y cuatro dientes adheridos a ese mango", o bien (b) "un tenedor compuesto de un mango cilíndrico, un primer diente adherido a dicho mango, un segundo diente adherido a dicho mango, un tercer diente adherido a dicho mango, y un cuarto diente adherido a dicho mango". Y el supuesto infractor sería un tenedor con tres dientes. Cfr. ADELMAN, Patent Law, cit. nota $\mathrm{n}^{\circ} 19$, p. 719.

${ }^{26}$ Eagle Comtronics, Inc. v. Arrow Communications Laboratories, Inc., 305 F.3d 1303, 1317 (Fed. Circ. 2002).

27 PSN Illinois, LLC. v. Ivoclar Vivadent, Inc., 525 F.3d 1159 (Fed. Cir. 2008). Un resumen del caso se encuentra en HOEKMAN, Modern Judicial Interpretations, cit. nota $n^{\circ} 22$, p. 18. En el mismo sentido, Freedman Seating v. American Seating: es preciso considerar todas las circunstancias y evaluar si el supuesto equivalente podría considerarse un cambio insustancial en la materia reivindicada, sin dejar desprovista de significado a la pertinente limitación (HOEKMAN, Modern Judicial Interpretations, cit. nota ${ }^{\circ}{ }^{22}$, p. 20). El fallo completo se encuentra en 420 F.3d 1350 (Fed. Cir. 2005).
} 
VAN WEEZEL, Alex. "El delito de infracción de una patente por equivalencia o por imitación".

a detectar una infracción en aquellos casos en que la literalidad de la reivindicación no comprende la variante infractora, es decir, cuando falta realmente un elemento literal en la reivindicación. Por otro lado, sin embargo, la regla de la totalidad de los elementos impide la aplicación de la teoría cuando falta, desde la perspectiva literal, un elemento de la reivindicación que calce con la variante infractora. Esta inconsistencia explica buena parte de las oscilaciones en la jurisprudencia sobre aplicación de la regla.

Por eso es que, en la práctica, la regla de la totalidad de las limitaciones se ha entendido en repetidas oportunidades como un análisis de la sustancialidad de las diferencias entre las reivindicaciones y los productos o procedimientos supuestamente infractores. Si el elemento que falta crea una diferencia sustancial, la regla produce el efecto de impedir la infracción. Si el elemento que falta no crea una diferencia sustancial, la doctrina de los equivalentes operará para afirmar la existencia de una infracción. ${ }^{28}$ Desde luego, esto produce entre otros el efecto de desplazar el asunto de la equivalencia, que de ser una cuestión primordialmente fáctica pasa a ser una de índole primordialmente valorativa.

c) El caso Corning Glass.

Sentando un precedente que luego será seguido por varios otros fallos (como el que recayó en el ya mencionado caso Eagle, de 2002), el Circuito Federal determinó en Corning Glass que

"si bien para afirmar la equivalencia es necesario encontrar en el aparato acusado de infracción un equivalente para cada uno de los elementos de la reivindicación, eso no significa necesariamente que deba encontrarse en un mismo y correspondiente componente del aparato acusado (aunque esto último sea la regla general)". ${ }^{29}$

En el caso concreto, el invento se refería a la construcción de una fibra óptica. La fibra óptica se compone en general de un núcleo y una cubierta, ambos hechos de una especie de cristal, y la invención patentada consistía en disminuir el "rebote" de la luz conducida por el núcleo incorporando un dopante al núcleo que incrementa su índice de refracción con respecto a la cubierta. Así aparecía reflejado en la reivindicación. El producto acusado de infracción, en cambio, obtenía el mismo efecto pero incorporando un dopante a la cubierta que disminuye su índice de refracción de la luz. El Circuito Federal consideró que existía una infracción por equivalencia.

Además, el tribunal estableció en Corning Glass que 'la palabra 'elemento' de una reivindicación puede ser utilizada tanto para designar una limitación singular como para designar una serie de limitaciones que, tomadas en su conjunto, constituyen un componente de la invención patentada". ${ }^{30}$ Este criterio hace explícita una flexibilización de la fórmula adoptada en Pennwalt, ${ }^{31}$ que ya se había venido produciendo en la jurisprudencia del

\footnotetext{
${ }^{28}$ ADELMAN, Patent Law, cit. nota ${ }^{\circ}$ 19, p. 714. Cfr. también Sears Petroleum \& Transport v. Archer Daniels Midland, 558 F.Supp.2d 273 (N.D. N.Y. 2008); Berger v. Ohio Table Pad Co., 539 F.Supp.2d 1069 (N.D. Ind. 2008).

${ }^{29}$ ADELMAN, Patent Law, cit. nota ${ }^{\circ} 19$, p. 714.

${ }^{30}$ Corning Glass Works v. Sumitomo Electric USA, Inc., 868 F.2d 1251, 1259 (Fed. Cir. 1989).

${ }^{31}$ Ver supra nota $\mathrm{n}^{\circ} 12$.
} 
Polít. crim. Vol. 8, No 15 (Julio 2013), Art. 5, pp. 170 - 209.

[http://www.politicacriminal.cl/Vol_08/n_15/Vol8N15A5.pdf]

Circuito Federal por las razones que se han apuntado precedentemente. Mientras Pennwalt rechaza un análisis que combine limitaciones o las agrupe, con lo que disminuyen las posibilidades de una infracción, Corning Glass acepta bajo ciertas condiciones este procedimiento. En términos prácticos, resulta claro que, de acuerdo a la doctrina de Corning Glass, no es irrelevante la forma como esté formulada una reivindicación, pues mientras más sean los elementos y limitaciones en los cuales se descomponga el invento, más posibilidades existirán de que el tribunal pueda combinarlos de un modo tal que le permita apreciar una infracción de la patente, si es que estima que ello resulta procedente desde el punto de vista - que entonces pasa a ser decisivo- de la ausencia de diferencias sustanciales.

Por ejemplo: en un procedimiento patentado, las etapas A, B y C son tecnología nueva y no obvia, mientras que la etapa $\mathrm{D}$ es bien conocida en el arte previo. Supongamos que el procedimiento acusado de infracción considera las etapas $A^{\prime}+B^{\prime}+C^{\prime}+D$, donde la etapa $A^{\prime}$ presenta diferencias sustanciales respecto de A, la etapa B' presenta diferencias sustanciales respecto de $\mathrm{B}, \mathrm{y} \mathrm{C}^{\prime}$ presenta diferencias sustanciales respecto de C. Sin embargo, cuando las tres etapas se consideran en su conjunto o como un todo, las diferencias entre $\mathrm{A}+\mathrm{B}+\mathrm{C}$ y $\mathrm{A}^{\prime}+\mathrm{B}$ ' $+\mathrm{C}$ ' son insustanciales. La etapa $\mathrm{D}$ es común a ambos procedimientos. La enseñanza de Corning Glass es que al inventor le conviene reivindicar en términos comprehensivos, que incluso se extiendan a aspectos cubiertos por el arte previo, si están insertos en un procedimiento novedoso. De esta forma, al momento de la infracción, el tribunal tendrá un campo de acción suficiente para estimar que aquella existe por equivalencia y sin contradecir la regla de la totalidad de las limitaciones. En efecto, si en el ejemplo la reivindicación sólo hubiera comprendido $\mathrm{A}+\mathrm{B}+\mathrm{C}$, sería muy difícil afirmar la equivalencia, lo que en cambio resulta posible porque existe el componente $\mathrm{D}$, que permite contemplar la patente infringida y el procedimiento infractor como compuestos, cada uno con dos elementos equivalentes entre sí. ${ }^{32}$

\subsubsection{El estoppel que emana de la historia del otorgamiento de la patente.}

La historia del expediente administrativo de otorgamiento de la patente puede cumplir dos funciones muy distintas entre sí. La primera función está estrechamente ligada a la doctrina de los equivalentes y constituye un límite objetivo a su aplicación. Esta función es propia del derecho de patentes estadounidense y no está reconocida en todos los ordenamientos jurídicos. La segunda función es más tenue y a la vez más general, pues en ella la historia opera como criterio auxiliar de interpretación de las reivindicaciones. A continuación analizaremos por separado ambas funciones.

a) El estoppel de la historia de la concesión.

Funcionando como estoppel, la historia de la concesión es una concreción en el ámbito de las patentes del principio jurídico venire contra factum proprium non valet. En síntesis, cuando el solicitante de una patente ha limitado o modificado una reivindicación para evitar su rechazo por parte de la autoridad administrativa, no puede luego -en un juicio infraccional- expandir el sentido de esa reivindicación de tal modo que incluya la materia

\footnotetext{
${ }^{32}$ El ejemplo está tomado de ADELMAN, Patent Law, cit. nota ${ }^{\circ}$ 19, p. 714.
} 
VAN WEEZEL, Alex. "El delito de infracción de una patente por equivalencia o por imitación".

previamente excluida o su equivalente, o bien omitiendo limitaciones que se había visto obligado a añadir.

El estoppel es reconocido como tal en los Estados Unidos e, indirectamente, en otras jurisdicciones como la japonesa. En cambio no se le reconoce, en general, en el ámbito europeo. Así se determinó además en la Revisión de la Convención Europea sobre Patentes (EPC) celebrada en el año 2000, donde se rechazó expresamente la introducción del estoppel de la historia del expediente y se reafirmó que el alcance de las patentes se determina sólo a partir de las reivindicaciones, con ayuda de la memoria descriptiva y los dibujos. Los argumentos y limitaciones vertidos o adoptados durante la tramitación de la concesión de la patente no cumplen función alguna. ${ }^{33}$ Como es obvio, con esto no se pretende afirmar que la doctrina de los actos propios carezca de reconocimiento en el derecho europeo. Desde luego que se la reconoce, tanto en el derecho civil (por ejemplo, en Alemania se entiende que está contenida en el § 242 BGB) como en el derecho penal (donde da origen a la posición de garante conocida como "confianza especial""34). Simplemente ocurre que los avatares del proceso de otorgamiento de la patente en sede administrativa no van a tener la categoría de "actos propios", con el severo efecto preclusivo que les atribuye la doctrina del venire contra factum proprium. Ello no obsta a que sí surtan tal efecto, por ejemplo, las acciones judiciales intentadas por el titular de una patente.

Con respecto a los Estados Unidos, la doctrina fundamental sobre el estoppel se encuentra también en Warner-Jenkinson. En esta sentencia se reafirma la importancia de la historia de la tramitación, pero al mismo tiempo se establece que el estoppel no se extiende a todo argumento vertido o restricción incorporada por el solicitante durante ella, sino únicamente a aquellas restricciones cuyo objeto preciso era evitar el arte previo, o bien, hacerse cargo de objeciones de la oficina de patentes que, de ser efectivas, habrían impedido el otorgamiento de la patente por una razón sustancial, como la obviedad. ${ }^{35}$ El fallo abunda en referencias a otras sentencias que establecen el mismo criterio. Por lo tanto, el estoppel no se configura cuando se trata simplemente de precisiones o aclaraciones del solicitante en orden a explicar el tenor de su solicitud o de las reivindicaciones que ha formulado. ${ }^{36}$ Tampoco lo configuran, según la jurisprudencia más reciente (Festo Corp. v. Shoketsu Kinzoku Kogyo Kabushiki Co., Ltd., 2002), las referencias a una aplicación preferente o a las ventajas del invento que se realicen en la memoria descriptiva. ${ }^{37}$

\footnotetext{
${ }^{33}$ BARDEHLE, Heinz, "Die Rolle der Äquivalente und des Erteilungsverfahrens bei der Bestimmung des Schutzbereichs von Patenten", Int'l Ass'n for the Protection of Intellectual Prop., Q175, Working Comm. Group Report (Germany) 3, disponible para los miembros de la AIPPI en https://www.aippi. org/download/commitees/175/GR175 germany.pdf [visitado el 08.03.2013].

${ }^{34}$ Cfr. JAKOBS, Günther, Strafrecht, Allgemeiner Teil. Die Grundlagen und die Zurechnungslehre, $2^{\mathrm{a}}$ ed., Berlin: De Gruyter, 1991, pp. 824 y ss.

${ }^{35}$ En un sentido análogo a como no es patentable en Chile lo que señala el art. 37 de la Ley 19.039.

${ }^{36}$ KIEFF et al., Principles of patent law, cit. nota ${ }^{\circ} 18$, p. 926.

${ }^{37}$ Al respecto véase HOEKMAN, Modern Judicial Interpretations, cit. nota ${ }^{\circ} 22$, p. 51.
} 
Polít. crim. Vol. 8, No 15 (Julio 2013), Art. 5, pp. 170 - 209.

[http://www.politicacriminal.cl/Vol_08/n_15/Vol8N15A5.pdf]

Por su parte, la doctrina del Circuito Federal ha establecido ${ }^{38}$ que para determinar si concurre el estoppel es preciso considerar "la manera en que se restringieron las reivindicaciones durante la tramitación; las razones por las cuales se efectuaron tales restricciones; los principios de equidad y de protección de los derechos que subyacen a los diversos argumentos, y los hechos del caso particular". ${ }^{39}$ De manera que el estoppel no funciona como una especie de comodín ni tiene un efecto automático.

\section{b) El expediente administrativo como elemento auxiliar en la interpretación de las patentes.}

Aunque en principio sólo cabe echar mano de la historia de la concesión de una patente cuando se trata de limitar el ámbito de aplicación de la doctrina de los equivalentes, ${ }^{40}$ cuando las reivindicaciones adolecen de una cierta imprecisión o sus términos parecen demasiado amplios en una primera aproximación, no es inusual que los tribunales particularmente en los Estados Unidos- utilicen la historia como criterio auxiliar de interpretación. Por esta vía, y en la medida en que la doctrina de los equivalentes responde a un modelo de interpretación teleológica de las reivindicaciones, la historia de la concesión podría limitar indirectamente la aplicación de la doctrina.

Uno de los casos fundamentales en esta materia es Omega Engineering, Inc. v. Raytek Corp., 334 F.3d 1314 (Fed. Cir. 2003). En esa oportunidad, el Circuito Federal estimó que utilizar la historia como criterio interpretativo era una consecuencia de la función de publicidad y certeza que deben cumplir las patentes respecto de los terceros. Sin embargo, en la misma causa declaró que no correspondía aplicar tal criterio cuando el abandono de un elemento inicialmente reivindicado o la restricción de las reivindicaciones era "ambigua". La renuncia deber ser, por el contrario, "clear and unmistakable".

Años antes, el Circuito Federal ya había dejado establecido en E.I. Du Pont de Nemours \& Co. v. Phillips Petroleum Co., 849 F.2d 1430 (Fed. Cir. 1988), que, al interpretar las reivindicaciones, los tribunales "deben recordar que ellas son las que definen la invención. Las ayudas interpretativas, como la memoria o la historia de la concesión de la patente, sólo pueden utilizarse para interpretar los términos incluidos en las reivindicaciones. Ellas no pueden utilizarse, por el contrario, para re-escribir las reivindicaciones o para añadir limitaciones que no fueron incluidas por el solicitante". ${ }^{41}$ Por tales razones, el Circuito Federal rechazó una interpretación de la patente realizada por el tribunal de distrito, en la cual se incluían dos características del invento que el solicitante había descrito en la memoria, pero que no había incluido en el texto de las reivindicaciones.

\section{c) La situación en Chile.}

Como queda en evidencia de lo expuesto, el estoppel de la historia de concesión de la patente ha sido desarrollado jurisprudencialmente en los Estados Unidos a través de un case

\footnotetext{
${ }^{38}$ Cfr. LaBounty Manufacturing, Inc. v. U.S. International Trade Commission (1989); HOEKMAN, Modern Judicial Interpretations, cit. nota ${ }^{\circ} 22$, p. 123.

${ }^{39}$ Cfr. HOLZMANN, Richard T., Infringement of the United States Patent Right: A Guide for Executives and Attorneys, Westport: Quorum Books, 1995, pp. 122 y ss.

${ }^{40}$ MOORE et al., Patent Litigation and Strategy, cit. nota ${ }^{\circ} 22$, p. 310.

${ }^{41}$ HOLZMANN, Infringement of the United States Patent Right, cit. nota n ${ }^{\circ}$ 39, p. 122.
} 
law que procura aplicar al derecho de patentes la doctrina de los actos propios. La ausencia absoluta de un desarrollo semejante en Chile, así como el fundamento de equidad -evitar el "fraude a la patente"- que subyace a la praxis en la materia, permiten concluir que en el sistema chileno la historia de la concesión de la patente no puede funcionar como un estoppel. $^{42}$ Tal como se señaló respecto del caso europeo, esto no significa que la doctrina de los actos propios no tenga aplicación en el derecho chileno, sino sólo que en el ámbito del derecho de patentes -y concretamente en lo que respecta a los procesos infraccionaleslos actos del solicitante en el procedimiento administrativo de otorgamiento de una patente no surten el efecto preclusivo que el case law de los Estados Unidos atribuye, en su ámbito, a similares manifestaciones de voluntad. En esta materia, el derecho nacional de patentes sigue la tendencia europea y no la estadounidense.

Con respecto a la historia como criterio auxiliar de interpretación, es preciso tener en cuenta que la interpretación de las patentes debe realizarse según el art. 49 inciso $3^{\circ}$ de la Ley y el art. 44 inciso $1^{\circ}$ del Reglamento. De acuerdo a estas normas, que también siguen la tendencia europea, ${ }^{43}$ el alcance de la protección otorgada por la patente se determina por el contenido de las reivindicaciones, las cuales por lo mismo constituyen el único objeto de interpretación; la memoria descriptiva y los dibujos sólo sirven como elementos auxiliares para interpretar las reivindicaciones. La regulación positiva no contiene, en cambio, referencia alguna a la historia del expediente como criterio interpretativo. Aunque ello no implica que la historia de la concesión de una patente carezca de toda relevancia al momento de interpretar su alcance, ciertamente limita bastante la utilidad de este recurso y el peso que puede asignarle el juzgador a las conclusiones que su uso pueda sugerir. Las razones que explican esta importante diferencia con el derecho de los Estados Unidos son variadas. Entre ellas se encuentra el hecho de que en ese país el procedimiento de concesión de las patentes se encuentra regulado en forma muy detallada por el derecho escrito, y que esta regulación exhibe diferencias importantes con la chilena. Por ejemplo, en Chile no existe como requisito de la solicitud de patente el señalamiento del "best mode" (realización preferida) del invento, que sí está previsto en la U.S. Patent Act. ${ }^{44}$

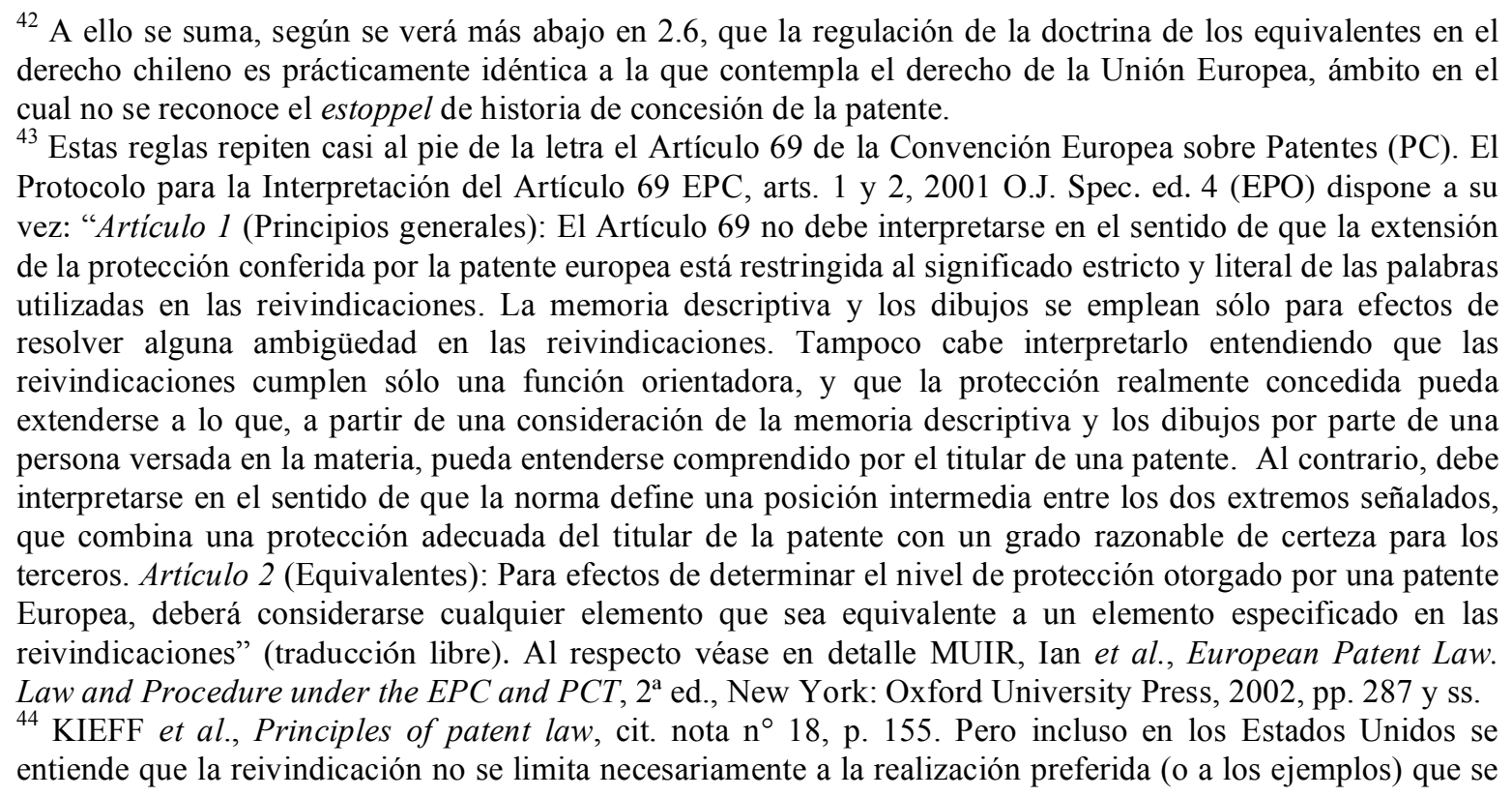


Polít. crim. Vol. 8, No 15 (Julio 2013), Art. 5, pp. 170 - 209.

[http://www.politicacriminal.cl/Vol_08/n_15/Vol8N15A5.pdf]

2.4.3. Doctrina de la dedicación o revelación al público.

Conforme a esta doctrina, no es posible invocar la teoría de los equivalentes en relación con aquellos aspectos que fueron revelados por el solicitante de una patente en la memoria descriptiva o en los dibujos, pero respecto de los cuales no realizó ninguna reivindicación. Por razones de certeza y de interés público asociadas al mismo sistema de reivindicaciones, se entiende que en tales casos el solicitante ha renunciado a la protección de la patente y ha dedicado o regalado al público ese aspecto de la invención ("contribution to the public").

La doctrina se remonta al siglo XIX (Miller v. Bridgeport Brass Co., 104 U.S. 350 [1881]), y ha sido seguida en numerosos fallos tanto de la Corte Suprema como del Circuito Federal de los Estados Unidos.

\subsubsection{El arte previo.}

No es posible extender el alcance de una patente por equivalencia en términos tales que aquellos aspectos que formaban parte del arte previo al tiempo de su solicitud, resulten comprendidos por la extensión interpretativa de la patente y, en consecuencia, puedan ser objeto de infracción. La limitación podría extenderse también a materias que al tiempo de la solicitud resultaban obvias de acuerdo al arte previo. Esta limitación se refiere a la extensión interpretativa por equivalencia, y por lo tanto no afecta a aquellos elementos de arte previo que han sido expresamente considerados en la literalidad de las reivindicaciones. En este último caso, se entiende que la reivindicación sólo se refiere a la particular forma de aplicarlos, o bien, que su mención resulta indispensable únicamente para delimitar el invento.

La sentencia fundamental al respecto en los Estados Unidos recayó en el caso Wilson Sporting Goods Co. v. David Geoffrey \& Associates (904 F.2d 677), resuelto por el Circuito Federal en 1990 en términos muy semejantes a una sentencia previa del Tribunal Federal alemán en el caso conocido como Formstein (BGHZ 98, 12). La Corte Suprema ha denegado sistemáticamente el certiorari cuando se ha pretendido cuestionar la doctrina de este fallo.

Trataremos con más de detalle esta limitación del arte previo una vez que se haya analizado el ámbito propio de las infracciones por imitación, debido a la particular trascendencia que tiene respecto de esta segunda forma infracción no literal de una patente.

ha señalado en la memoria descriptiva, a no ser que la memoria considere la realización preferida como el invento mismo (cfr. entre muchos otros Texas Instruments Inc. v. United States Int'l Trade Comm'n, 805 F.2d 1558 [Fed. Cir. 1986]). Al respecto, MOORE et al., Patent Litigation and Strategy, cit. nota ${ }^{\circ} 22$, pp. 287 y ss. Otra diferencia entre el derecho chileno de patentes y el derecho positivo estadounidense es la especial regulación que contiene este último respecto de las reivindicaciones que están redactadas como medios o pasos para realizar una función que se especifica. Estas cláusulas están afectas a ciertos requisitos de formulación en relación con la correspondiente memoria descriptiva. 35 U.S.C.S. § 112, par. 6 (LexisNexis 2011). 
VAN WEEZEL, Alex. "El delito de infracción de una patente por equivalencia o por imitación".

\subsection{Otros límites a la aplicación de la doctrina de los equivalentes.}

En términos generales, se observa en la jurisprudencia estadounidense progresivo retorno al fundamento de equity de la doctrina de los equivalentes, tal como aparece recogido en Graver Tank. Esto significa que se ha impuesto una mirada menos formalista en el análisis de la infracción, lo que se traduce en una pérdida de fuerza de la regla de la totalidad de las limitaciones. Como contrapartida, se concentran las restricciones a la doctrina de los equivalentes en los demás criterios que se han reseñado - por ejemplo, la limitación del arte previo-, y se recuperan otros criterios auxiliares destinados a establecer si ha existido o no una especie de "fraude a la patente". Entre estos últimos cabe destacar los siguientes:

\subsubsection{Autonomía en el desarrollo del producto infractor.}

Se trata de un criterio que ya había sido enunciado en Graver Tank, con la constatación de Justice Jackson en el sentido que "el expediente no contiene evidencia de ningún tipo en orden a que Lincolnweld [el producto acusado de infracción] sea el resultado de una investigación independiente o de experimentos" realizados por el acusado. ${ }^{45}$

\subsubsection{Si el supuesto infractor tuvo acceso a detalles del invento.}

Uno de los aspectos que resultaron decisivos en Graver Tank, y que ha sido luego recogido y destacado por la literatura, fue el hecho de que la invención patentada haya sido el resultado de un proyecto de investigación conjunto, al cual en su oportunidad tuvo acceso el acusado. ${ }^{46}$

La recuperación de estos criterios y la idea de evitar un "fraude a la patente" coinciden en Chile con la doctrina y la jurisprudencia, las que, a juzgar por los antecedentes disponibles, privilegian desde antiguo una concepción que apunta en esta misma dirección. El hecho que el Título X de la Ley 19.039 -introducido en 2005 por la Ley 19.996- haya dispuesto que también el tribunal civil debe apreciar la prueba conforme a las reglas de la sana crítica al conocer de las infracciones, constituye también un indicio de que el legislador comparte y sanciona dicha tradición.

\subsection{La doctrina de los equivalentes en Chile: los "equivalentes técnicos" en el Reglamento de la Ley 19.039.}

Como se ha visto, la doctrina de los equivalentes se aplica tanto en los Estados Unidos como en la Unión Europea, y en ambos casos cuenta con un amplio reconocimiento jurisprudencial y con un cierto respaldo positivo. En el caso de Europa, la Revisión del Tratado Europeo sobre Patentes suscrita en Munich en el año 2000 exige "considerar en la determinación del ámbito de protección de una patente aquellos elementos que son equivalentes a los que se mencionan en las reivindicaciones". En los Estados Unidos, se reconoce la equivalencia para los efectos de limitar las reivindicaciones relativas a

\footnotetext{
${ }^{45}$ HOLZMANN, Infringement of the United States Patent Right, cit. nota $\mathrm{n}^{\circ} 39$, p. 104.

${ }^{46}$ HOLZMANN, Infringement of the United States Patent Right, cit. nota $n^{\circ} 39$, p. 118.
} 
Polít. crim. Vol. 8, No 15 (Julio 2013), Art. 5, pp. 170 - 209.

[http://www.politicacriminal.cl/Vol_08/n_15/Vol8N15A5.pdf]

"medios" a aquellos que resulten equivalentes a los que se muestran expresamente en la memoria descriptiva de la patente. ${ }^{47}$

En Chile, y con un lenguaje absolutamente inequívoco si se tiene en cuenta el contexto resumido en los apartados anteriores de esta sección, el Reglamento de la Ley 19.039 refrendó positivamente la doctrina de los equivalentes -ya recogida en el Reglamento de 1991 y reconocida por la doctrina y la jurisprudencia- a través de la definición de "equivalente técnico" contenida en el art. $2^{\circ}$ : "elemento o medio que realiza la misma función que aquel que está reivindicado en una invención, de la misma manera y produciendo el mismo efecto o resultado señalado en la reivindicación".

La Ley 19.039 y sus normas complementarias no contienen otras menciones explícitas a la doctrina de los equivalentes, pero ello no es necesario, pues la doctrina no es otra cosa que una forma de interpretar las reivindicaciones para establecer su alcance en el contexto de un juicio acerca de su infracción. Por lo tanto, se trata de una tarea que corresponde al juez de acuerdo a las normas generales. El Reglamento, en su art. $2^{\circ}$, sólo da cuenta de que el derecho chileno de propiedad industrial reconoce la doctrina de los equivalentes, y le indica al tribunal someramente que ella se inscribe en la tradición estadounidense de la "triple identidad".

En consecuencia, resultan plenamente aplicables al derecho chileno las consideraciones de fondo que se han realizado en los apartados anteriores, sin perjuicio de las diferencias que emanan de los principios generales que informan nuestro ordenamiento y de las particularidades regulatorias que presenta. ${ }^{48}$ Una de estas particularidades es la protección contra imitaciones, que se analiza en la sección siguiente. En este análisis se toma como punto de partida lo evidente: si la recepción normativa de la doctrina de los equivalentes asume el criterio de la triple identidad, entonces la equivalencia se juzga de acuerdo a la regla de la totalidad de las limitaciones. Esto podría implicar -dependiendo de las relaciones que la Ley establezca entre las infracciones por equivalencia y por imitaciónque el tenor de las reivindicaciones integra por igual las definiciones típicas del art. 52 de la Ley 19.039, en sus letras a), c) y d).

\section{El delito de imitación de un invento con solicitud de patente en trámite.}

Lo expuesto en las secciones anteriores permite ahora hacerse cargo de una importante particularidad del derecho chileno de patentes, situándola en su contexto. Esta particularidad consiste en que la Ley contempla una segunda forma de infracción no literal

\footnotetext{
${ }^{47}$ En lo pertinente: "Un elemento de una reivindicación puede expresarse como medio o paso para llevar a cabo una función específica, sin señalar explícitamente la estructura, los materiales o los actos complementarios. En tales casos, dicha reivindicación será interpretada de tal modo que alcance a cubrir la estructura, los materiales o actos correspondientes que se hallan descritos en la memoria descriptiva y sus equivalentes" 35 U.S.C.S. $§ 112$ (LexisNexis 2011).

${ }^{48}$ MELOSSI, "Interpretación de las patentes de invención”, cit. nota $n^{\circ} 12$, p. 234 y s., señala, por ejemplo, que el art. $2^{\circ}$ del Reglamento debe entenderse en el sentido de que el equivalente debe cumplir la misma función en la misma forma, pero sólo "con miras" o "en vista" de producir el mismo resultado. Ello implica reducir teleológicamente la expresión "produciendo el mismo efecto o resultado señalado en la reivindicación", atendido que "la patente no protege un efecto del invento".
} 
VAN WEEZEL, Alex. "El delito de infracción de una patente por equivalencia o por imitación".

de las patentes, que se suma a la infracción por equivalencia: la imitación de un invento con solicitud de patente en trámite. Para analizar esta protección adicional y más amplia de los derechos del inventor será preciso referirse tanto al régimen de protección de la patente en trámite, como al fundamento legal y alcance de la infracción por "imitación".

\subsection{Protección de la patente en trámite.}

\subsubsection{Clases de protección.}

La Ley 19.039 y su Reglamento definen las características y alcance de la protección que otorga una patente de invención. Por ejemplo, que tal protección dura en total 20 años, contados desde la fecha de presentación de la solicitud (art. 39 de la Ley); que se extiende a todo el territorio de la República (art. 49 de la Ley); que comprende los productos en el caso de los procedimientos (art. 49 de la Ley); que las reivindicaciones definirán la materia que será objeto de la protección (art. 41 del Reglamento); que el preámbulo de la reivindicación define el invento en la materia a que se refiere (art. 43 del Reglamento); que la caracterización es la parte medular de una cláusula (art. 43 del Reglamento); que al solicitante le corresponden ciertos derechos de propiedad industrial (art. $3^{\circ}$ del Reglamento); etc. Desde una perspectiva dinámica, el sistema chileno contempla dos clases de protección:

- la protección que otorga la solicitud de patente, que cubre el periodo que comienza con la presentación de la solicitud y se extiende hasta su otorgamiento, y

- la protección que otorga la patente, que cubre el periodo que comienza con el otorgamiento de la patente y se extiende hasta su vencimiento.

La primera clase de protección, la que otorga la patente en trámite, es muy importante para el legislador. Ello se manifiesta no sólo en las normas penales, sino también en el rol que juega esta protección en la arquitectura de la Ley 19.039. Por ejemplo, cuando se refiere en general a la interpretación de las patentes, el art. 49 inciso $3^{\circ}$ de la Ley no deja de lado las patentes en trámite, y dispone expresamente que "el alcance de la protección otorgada por la patente o la solicitud de patente se determinará" de la forma que indica. Asimismo, el inciso final del art. 53 de la Ley establece que cuando se comercialicen o fabriquen productos a que se refiere una solicitud de patente en trámite, debe indicarse esta situación para poder ejercer las acciones penales que contempla la Ley. Adicionalmente se prevé la posibilidad de solicitar la denominada "protección suplementaria", si es que el procedimiento ha tardado más de cinco años por demoras injustificadas (art. 53 bis 1 y ss. de la Ley). Es decir, si bien el tiempo de tramitación por lo general forma parte del tiempo total de veinte años que dura la protección de la patente, ese plazo puede ampliarse en caso de demora injustificada de la tramitación.

\subsubsection{Características específicas de la patente en trámite.}

El último ejemplo consignado en el apartado anterior pone también en evidencia que entre la protección de la patente concedida y la que otorga la patente en trámite existen diferencias sustanciales. La patente en trámite otorga una protección provisoria, pero 
Polít. crim. Vol. 8, No 15 (Julio 2013), Art. 5, pp. 170 - 209.

[http://www.politicacriminal.cl/Vol_08/n_15/Vol8N15A5.pdf]

además condicional (depende del hecho futuro e incierto de que se conceda la patente). La patente en trámite no confiere acciones contra una eventual infracción mientras no sea otorgada en definitiva (art. 48 de la Ley). Especialmente relevante es la circunstancia de que, con anterioridad al otorgamiento de la patente, existe incertidumbre acerca de cuál será exacta y definitivamente el objeto de protección de la patente. Por ejemplo, el art. 20 del Reglamento establece que "el Departamento podrá en cualquier momento del procedimiento determinar la modificación o división de la solicitud de patente". El mismo solicitante puede introducir cambios importantes a la solicitud hasta antes de que se evacúe el informe pericial respectivo, y con posterioridad a él también la puede seguir modificando dentro de ciertos límites. Por lo tanto, en muchos casos el pliego de reivindicaciones concedido ni siquiera habrá existido al momento del conflicto.

Estas y otras características, pero especialmente las dos últimas mencionadas -ausencia de acciones, indeterminación del objeto preciso-, dan lugar a un particular régimen de protección cuya naturaleza fue realzada aun más por la modificación que la Ley 19.996 introdujo a la Ley sobre Propiedad Industrial, según se explica en el apartado siguiente.

\subsection{Fundamento y alcance de la infracción por imitación.}

El alcance de la protección de una patente en trámite contra las imitaciones depende en buena parte de la forma como el legislador ha entendido su fundamento. Por eso, antes de abordar el concepto de imitación y los límites de la imitación típicamente relevante es preciso referirse brevemente a la modificación del régimen penal introducida en el año 2005 por la Ley 19.996.

\subsubsection{Efectos de la modificación obrada por la Ley 19.996.}

Antes de la modificación de 2005, el art. 52 letra d) de la Ley contemplaba sanciones penales para el "que cometiere defraudación imitando una invención patentada" ${ }^{49}$ Por lo tanto, se castigaba en general la infracción de una patente no sólo cuando era cometida mediante la reproducción literal o por equivalencia del mismo producto o proceso materia del invento patentado, sino también mediante una imitación, una variante cercana aunque no equivalente.

Sin embargo, la Ley 19.996 sustituyó la letra d) citada por una norma similar a la contenida en la antigua letra e) del mismo artículo. Conforme a la nueva redacción, se castiga a todos "los que maliciosamente imiten o hagan uso de un invento con solicitud de patente en trámite, a menos de que, en definitiva, la patente no sea concedida". ${ }^{50} \mathrm{El}$ precepto impide no sólo el uso del invento (o procedimiento: art. 31 de la Ley) cuya solicitud de patente está en trámite, sino además el uso de dispositivos o procedimientos similares que puedan considerarse una "imitación" del invento con solicitud de patente en trámite. ${ }^{51}$ Esta nueva

\footnotetext{
${ }^{49}$ El antiguo texto de la norma era del siguiente tenor: "Artículo 52.- Será castigado con multa a beneficio fiscal, de 100 a 500 Unidades Tributarias Mensuales: (...) d) El que cometiere defraudación imitando una invención patentada".

${ }^{50}$ La antigua letra e) era del siguiente tenor: "El que maliciosamente imitare o hiciere uso de un invento con solicitud de patente en trámite, siempre que en definitiva la patente sea otorgada".

${ }^{51}$ Véase al respecto infra nota $n^{\circ} 63 \mathrm{y}$ el texto principal correspondiente.
} 
VAN WEEZEL, Alex. "El delito de infracción de una patente por equivalencia o por imitación".

configuración de las infracciones punibles responde a las peculiaridades del régimen al cual está sometida la patente en trámite. En efecto, la Ley considera una protección más amplia en su objeto que la que brinda a la patente ya concedida como una forma de restablecer el equilibrio a favor de quien ya ha solicitado la patente, ha divulgado su invento y debe someterse a la tramitación administrativa y a las oposiciones, a veces provenientes de las mismas personas que podrían convertirse en infractores.

Esta lectura de la modificación se ve confirmada por la historia de la Ley 19.996. En efecto, el Segundo Informe de la Comisión de Economía del Senado recoge en los siguientes términos los fundamentos de la inclusión de la nueva letra d) del art. 52:

“El autor de la propuesta señaló que, sin esta medida protectora, cualquiera puede poner en circulación un producto cuya patente está en tramitación y hacer vacuo el derecho que eventualmente obtenga el titular, porque ya el mercado estará copado o agotado. Se trata de tipificar un ilícito sin tener que esperar el resultado del trámite de obtención de la patente, que puede ser bastante extenso. Si no se otorga la patente, no habrá delito". ${ }^{2}$

A continuación, el informe consigna los reparos del antiguo Departamento de Propiedad Industrial, que se opuso al texto de lo que finalmente llegó a ser la letra d) del art. 52 de la Ley. Los argumentos que expusieron los representantes de ese organismo son del mayor interés, pues reflejan la trascendencia de la decisión legislativa:

"Los funcionarios del Departamento de Propiedad Industrial pusieron de manifiesto que todo el proyecto está orientado en el sentido de ADPIC, en orden a despenalizar las infracciones, las que tienen únicamente efectos civiles. Además, la norma sugerida protege una mera expectativa y castiga una conducta que, en definitiva, se consumará cuando se resuelva la solicitud de patente, de modo que los tribunales suspenderán el procedimiento, o la aplicación de penas, hasta que se despeje la cuestión previa de si hay o no patente. Agregaron que es una práctica usual de los grandes laboratorios pedir una serie de patentes afines a la que verdaderamente desean proteger, dejándolas luego abandonadas, sin tramitar". ${ }^{33}$

Como es bien sabido, las objeciones planteadas por los funcionarios del Departamento de Propiedad Industrial no fueron acogidas por los legisladores, de modo que se estableció el tipo penal en los términos descritos anteriormente. Pero esas objeciones tienen cierto valor interpretativo, pues al menos dan cuenta de que si bien el legislador renunció a la protección general que antes se concedía frente a las imitaciones, al mismo tiempo quiso mantener - tras una discusión específica al respecto- el tipo penal respecto de las patentes en trámite. Ello sólo puede explicarse a partir de las peculiaridades del régimen jurídico al

\footnotetext{
${ }^{52}$ Historia de la Ley $\mathrm{N}^{\circ} 19.996$ (editada por la Biblioteca del Congreso Nacional), p. 872.

${ }^{53}$ Además, se consignó que "de acuerdo al artículo 48 de la ley $\mathrm{N}^{\circ} 19.039$, la protección que da una patente rige desde que ella es solicitada, y que las medidas sobre observancia, que se introducen en virtud del nuevo Título $\mathrm{X}$ que se incorpora a la ley $\mathrm{N}^{\mathrm{o}} 19.039$, comprenden una serie de medidas precautorias e indemnizatorias que permitirán al titular de la patente resarcirse de los perjuicios que una conducta como la descrita en la letra e), en comento, pudiera llegar a causarle" (Historia de la Ley $\mathrm{N}^{\circ} 19.996$ [editada por la Biblioteca del Congreso Nacional], p. 872).
} 
Polít. crim. Vol. 8, № 15 (Julio 2013), Art. 5, pp. 170 - 209.

[http://www.politicacriminal.cl/Vol_08/n_15/Vol8N15A5.pdf]

que están sometidas estas últimas, en particular la ausencia de acciones y la indeterminación del objeto preciso mientras dure la tramitación.

\subsubsection{La infracción por imitación en la Ley 19.039: autonomía de la imitación.}

La Ley 19.039 conoce la infracción por imitación tanto en el ámbito de las patentes de invención como en el de las marcas comerciales. ${ }^{54}$ En lo que respecta a estas últimas, el art. 28 castiga a quienes usen una marca igual o "semejante" a otra ya inscrita. Esta semejanza debe entenderse como imitación, pues el art. 29 dispone el comiso de los utensilios y elementos directamente empleados para la "falsificación o imitación". En la misma línea, el art. 20 letra d) establece que no pueden inscribirse como marcas las imitaciones de algunos signos oficiales del Estado, ni tampoco las imitaciones de ciertas medallas, diplomas o distinciones.

Por otro lado, el art. 104 de la Ley permite colegir, en una interpretación sistemática, el sentido amplio en que el legislador usa la palabra "imitación". Tratándose de las indicaciones geográficas o denominaciones de origen de vinos y bebidas espirituosas, se señala que las acciones civiles proceden cuando la indicación geográfica o denominación de origen sea utilizada por quien no tiene derecho a hacerlo, aun cuando se acompañen de términos como "clase", "tipo", "estilo", "imitación", "u otras análogas". El núcleo semántico de la cláusula analógica que contiene la norma apunta con toda claridad a que la imitación de algo no es idéntica ni equivalente a lo imitado, pero podría cumplir una función semejante porque comparte con éste algunas propiedades decisivas.

Estas referencias muestran que la noción de imitación es relevante para la Ley, si bien en cada caso cumple funciones diversas y, por consiguiente, es apreciada desde perspectivas también diferentes. Mientras que en el ámbito marcario apunta a una posibilidad de sustitución del original por confusión de parecidos, en el caso de las denominaciones de origen se trata de un peligro de sustitución del original precisamente por su asociación explícita con él. En el caso de las patentes de invención, en cambio, se busca impedir el aprovechamiento por parte de terceros de la enseñanza divulgada en una solicitud de patente, por lo que el concepto de imitación no atiende a un peligro de confusión o asociación, sino al juicio de semejanza realizado por un experto en la materia.

Se puede observar, por lo tanto, que el concepto de imitación goza de autonomía en la regulación y no puede confundirse, por ejemplo, con el concepto menos amplio de equivalencia. Si bien en ambos casos se trata de infracciones no literales, la Ley y su Reglamento conocen, por un lado, la infracción literal o por equivalencia de las patentes concedidas, y la infracción literal, por equivalencia o por imitación de las patentes en trámite, por el otro. Si el concepto de equivalencia se confundiera con el concepto de imitación, las patentes ya concedidas sólo podrían infringirse literalmente, desde el momento en que la noción de imitación, en el ámbito de las patentes, sólo se contempla

\footnotetext{
${ }^{54}$ Tradicionalmente, la imitación sólo estaba asociada a las creaciones de forma y signos distintivos (cfr. por ejemplo, MASCAREÑAS, Los delitos contra la propiedad industrial, cit. nota $\mathrm{n}^{\circ}$ 7, pp. 149 y ss.), pero ello no tiene en cuenta lo que se señala a continuación en el texto.
} 
VAN WEEZEL, Alex. "El delito de infracción de una patente por equivalencia o por imitación".

respecto de las solicitudes que aún se encuentran en trámite. ${ }^{55}$ Resulta evidente que semejante conclusión no es compatible con el derecho de patentes chileno, con su evolución ni con el contexto teórico y práctico en el que se ha dictado.

\subsubsection{Qué significa imitar. La importancia interpretativa de la doctrina de los equivalentes.}

Durante la tramitación de una solicitud de patente no existe certeza acerca de cuál será el pliego de reivindicaciones que aprobará el INAPI, de modo que el contraste entre el texto aprobado de la patente y las aplicaciones o procedimientos acusados de infringirlo debe realizarse con cierta flexibilidad respecto de las infracciones ocurridas durante la tramitación de la patente. La Ley recoge esta flexibilidad interpretativa precisamente a través de la protección de la patente en trámite contra imitaciones, de manera que la utilización de un modelo teleológico de interpretación no es opcional para el tribunal.

Para hacer operativo dicho modelo, sin embargo, es preciso clarificar antes qué significa "imitar" en el sentido de la Ley. En esta tarea adquieren relevancia los desarrollos del derecho comparado que se han reseñado precedentemente, así como la manera en que ellos han sido recibidos en el ordenamiento jurídico chileno. En efecto, y según se verá, la doctrina de los equivalentes funciona como una especie de "bisagra" o punto intermedio entre la reproducción literal de un invento y su imitación, de tal manera que esta última se situará necesariamente un poco más distante de la infracción literal que la infracción por equivalencia, pero a la vez lo suficientemente cercana a ésta como para que el ámbito de protección que brinda una solicitud en trámite no resulte desproporcionado o excesivo.

\section{a) Infracción literal e infracción no literal.}

Una patente puede ser infringida en términos literales. Ello ocurrirá, por ejemplo, en los (raros) casos en que se reproduzca exactamente cada una de las etapas de un proceso, y cada etapa se realice del mismo modo que se define en el invento. Sin embargo, lo más común es que las infracciones no sean literales, pues el infractor modifica -por las razones que sea- algún aspecto de la invención. En ciertos casos, esta infracción no literal de la patente equivale al uso de la misma patente, y esa equivalencia se establece precisamente de acuerdo a los criterios de la doctrina de los equivalentes que se han revisado en las secciones anteriores y que el ordenamiento jurídico chileno reconoce.

\footnotetext{
55 De otra opinión MELOSSI, “Interpretación de las patentes de invención”, cit. nota n 12, p. 236 y s., quien sostiene que la patente ya concedida también puede infringirse por imitación conforme a la letra a) del art. 52 de la Ley. Esto es erróneo, pues sólo en caso de equivalencia puede entenderse que el infractor es funcionalmente idéntico o "lo mismo" que el invento patentado. Así quedó de manifiesto, por ejemplo, en una sentencia del Tercer Tribunal de Juicio Oral en lo Penal de Santiago (S. de 10.IX.2007, N Legal Publishing: 37852, recaída en el caso conocido como Iskimil vs. Plavix), donde con un voto disidente se condenó en virtud de la letra b) del antiguo art. 52 (infracción literal y por equivalencia), absolviendo el tribunal de las acusaciones por imitación: letras d) y e) de la versión anterior a la Ley 19.996 (cons. 12²). El acusado alegó que el producto farmacéutico denominado Iskimil utilizaba la forma cristalina 1 del compuesto clopidogrel hidrogenosulfato. La sentencia estableció, sin embargo, que el producto contenía clopidogrel hidrogenosulfato en forma cristalina 2, el mismo principio activo que se encuentra protegido por la patente de invención $\mathrm{N}^{\mathbf{}}$ 42.308 otorgada por el Departamento de Propiedad Industrial el 5 de enero de 2005.
} 
Polít. crim. Vol. 8, No 15 (Julio 2013), Art. 5, pp. 170 - 209.

[http://www.politicacriminal.cl/Vol_08/n_15/Vol8N15A5.pdf]

Así, por ejemplo, la Ley establece que se castigará a quienes "hagan uso de un procedimiento patentado" (art. 52 letra c]), y es justamente para saber si se ha hecho "uso de un procedimiento patentado" que se utiliza el concepto de equivalente técnico, de tal manera que no se burle la protección de la patente mediante artificios destinados a introducir diferencias irrelevantes para escapar a dicha protección. Un antiguo fallo estadounidense de gran influencia lo resume, en términos perfectamente aplicables al derecho chileno, del siguiente modo: "El equivalente sustancial de una cosa, en el sentido del derecho de patentes, es lo mismo que esa cosa; de tal manera que si dos artefactos realizan el mismo trabajo de sustancialmente el mismo modo, y alcanzan así sustancialmente el mismo resultado, ambos son lo mismo" (Union Paper-Bag Machine Co. v. Murphy, 97 U.S. 120 [1878]).

\section{b) Infracción no literal por imitación.}

En cambio, "imitar" no es lo mismo que fabricar, importar, etc. "un invento patentado" o "hacer uso" de un procedimiento patentado, ni siquiera por equivalencia. Y sin embargo, según se ha visto, también a las imitaciones se extiende la esfera de protección de la patente cuando ellas se cometen mientras la solicitud de patente del invento se encuentra en trámite (art. 52 letra d] de la Ley). Respecto de esta infracción por imitación, el concepto de equivalente técnico es fundamental, pues define el punto donde se deja atrás la equivalencia y comienza la imitación. Esta definición tiene una dimensión negativa, la de precisar por contraste lo que ya no es imitación, sino derechamente equivalencia o identidad. Pero también tiene una dimensión positiva, cuya trascendencia es aún mayor: como en el derecho positivo la equivalencia está asociada a la triple identidad, que es una aplicación de la regla de la totalidad de las limitaciones, la imitación está ligada desde un comienzo al tenor de las reivindicaciones de la patente y, en consecuencia, no responde a un juicio global de semejanza. Dicho de otro modo, la concepción restrictiva de la equivalencia que ha asumido el ordenamiento chileno obliga a interpretar el alcance de la imitación en términos igualmente restrictivos.

A continuación se realiza una propuesta para tal interpretación, precisando en primer lugar el alcance de la equivalencia de acuerdo al derecho positivo (c), y luego extrayendo las consecuencias para la definición del ámbito de la imitación (d).

c) Equivalencia en el derecho de patentes chileno según el artículo $2^{\circ}$ del Reglamento de la Ley 19.039.

Conforme al derecho chileno, se fabrica, importa, comercializa, etc. un invento patentado, o bien, se hace uso de un invento o procedimiento patentado, aunque se utilicen en parte elementos o medios diversos, si las variantes pueden considerarse equivalentes técnicos de los elementos o medios originales. Y conforme al art. $2^{\circ}$ del Reglamento, es equivalente técnico un elemento o medio que realiza la misma función que aquel que está reivindicado en una invención, de la misma manera y produciendo el mismo efecto o resultado señalado en la reivindicación. 
VAN WEEZEL, Alex. "El delito de infracción de una patente por equivalencia o por imitación".

Pero se ha visto que hay dos formas de interpretar el alcance de una patente en orden a determinar si una variante la infringe o no desde el punto de vista de la doctrina de los equivalentes. La primera posibilidad atiende al invento como un todo, mientras que la segunda exige analizar las diferentes partes o elementos de la reivindicación y de la variante supuestamente infractora, de tal manera que la acusación debe demostrar la presencia de cada elemento reivindicado o de su equivalente sustancial en el aparato acusado de infracción. Tanto la jurisprudencia estadounidense (cfr. en especial WarnerJenkinson) como la japonesa y, en cierto modo, también la europea, se han inclinado por una teoría de los equivalentes bajo la segunda variante, relegando a la categoría de criterio auxiliar la idea de la contemplación del invento como un todo. Resulta evidente que de esta manera se introduce una primera restricción relevante a la equivalencia.

Por otra parte, sin embargo, hay diversas formas de analizar las invenciones elemento por elemento y, en particular, se han ido decantando dos enfoques muy diferentes entre sí. Al estilo de Graver Tank, cabe determinar la equivalencia o su ausencia atendiendo a si las diferencias entre la invención patentada y el producto o procedimiento acusado de infracción son o no insustanciales. Sin duda que de este modo se añade una restricción adicional a la equivalencia, pero al mismo tiempo ello ocurre de un modo relativamente flexible, abierto a la ponderación del contexto de la patente, el arte previo y las circunstancias particulares del caso, tal como se señala expresamente en Graver Tank.

La alternativa consiste en sostener que la equivalencia exige una triple identidad, en cuanto a la función que cumple el elemento en cuestión, la forma en que la cumple y el resultado obtenido por él. Para que exista equivalencia, los artefactos deben realizar la misma función, en la misma forma, alcanzando un resultado idéntico al señalado en la reivindicación. Esta forma de analizar la equivalencia se introdujo con fuerza en Pennwalt, ${ }^{56}$ que sirvió de base a Warner-Jenkinson y luego a muchos otros fallos. Su expresión práctica o probatoria es la prohibición de que el análisis de la equivalencia termine por eliminar completamente o por vaciar de contenido algún elemento de la reivindicación o su fundamento técnico. Aunque, como se ha visto, también esta fórmula admite un cierto margen de flexibilidad al momento de definir qué es un elemento de la reivindicación, ${ }^{57}$ se trata de un estándar más restrictivo que el que atiende a la sustancialidad de las diferencias.

Ahora bien, si la definición contenida en el Reglamento considera equivalente técnico a "un elemento o medio que realiza la misma función que aquel que está reivindicado en una invención, de la misma manera y produciendo el mismo efecto o resultado señalado en la reivindicación", resulta palmario que tal definición se inscribe en la corriente más restrictiva dentro de la evolución reseñada, es decir, en la doctrina de la triple identidad que aparece delineada por el fallo Warner-Jenkinson, por oposición al criterio de Graver Tank basado en la sustancialidad de las diferencias.

\footnotetext{
${ }^{56}$ Pennwalt Corp. v. Durand-Wayland, Inc., 833 F.2d 931 (Fed. Cir. 1987) (en banc); cfr. HOLZMANN, Infringement of the United States Patent Right, cit. nota ${ }^{\circ} 39$, p. 87.

${ }^{57}$ Cfr. el comentario al caso Corning Glass, supra 2.4.1. letra c).
} 
Polít. crim. Vol. 8, No 15 (Julio 2013), Art. 5, pp. 170 - 209.

[http://www.politicacriminal.cl/Vol_08/n_15/Vol8N15A5.pdf]

d) Consecuencias de la definición de equivalencia para el concepto de imitación.

La imitación se encuentra en una zona que limita por un lado con la doctrina de los equivalentes $\mathrm{y}$, por el otro, con un invento que puede considerarse diferente del patentado, o bien, con una técnica que se confunde con el arte previo. En este apartado se analizará el primer límite, mientras que el límite del arte previo -que es común a las dos formas de infracción no literal- se tratará en la siguiente sección. Los contornos del argumento según el cual el supuesto infractor posee en realidad un invento diferente se obtienen al delinear los dos límites anteriores.

Aplicando lo desarrollado precedentemente, ahora con el fin de clarificar el concepto de infracción no literal por "imitación" en la Ley 19.039, habrá que concluir que ésta puede comenzar con una equivalencia prima facie, pero que, analizada en detalle, no cumple con la triple identidad en sentido estricto, es decir, allí donde aplicar la teoría de los equivalentes significaría eliminar por completo o vaciar de contenido algún elemento reivindicado. En tal caso no habría equivalencia, pero sí podría haber imitación.

También habrá que considerar como imitaciones los procedimientos o aplicaciones donde alguno o algunos de sus elementos no coinciden exactamente con alguno o algunos de los elementos reivindicados, pero tales diferencias pueden considerarse insustanciales -al estilo de Graver Tank-, si se ponderan teniendo en cuenta los elementos que son idénticos entre ambas. Del mismo modo habrá imitación si la falta de sustancialidad de las diferencias se constata después de agrupar funcionalmente elementos singulares, tanto en el patentado como en el acusado de infracción. Esta agrupación funcional es legítima, pues se trata de una reconstrucción coherente con la estructura que deben tener los pliegos de reivindicaciones de conformidad a la Ley, según se analizó al comentar la enseñanza del caso Corning Glass. $^{58}$

El límite se alcanza, no obstante, cuando en lugar de una agrupación funcional de elementos precisos en el objeto patentado y en el acusado de infracción sólo se tiene un análisis de ambos considerados como un todo. Si un análisis de este tipo concluyera que el objeto o procedimiento acusado de infracción resulta funcionalmente similar al patentado tanto en cuanto al problema que resuelve como a la forma en que lo hace, ello puede dar lugar a una infracción civil pero no al delito de imitación de una patente en trámite. Éste es el punto donde se intersectan, en el ordenamiento chileno, las posibilidades de extensión de la protección que brinda la patente y los límites que impone el principio de legalidad en materia penal. La ubicación de ese punto en el plano está dada por la recepción normativa de la regla de la totalidad de los elementos en su vertiente de la triple identidad. La imitación comienza allí donde no es posible hablar de triple identidad, pero aún hay espacio para discutir sobre la sustancialidad de las diferencias entre las reivindicaciones y los productos o procedimientos supuestamente infractores.

En consecuencia, el tenor de las reivindicaciones integra tanto el tipo penal de la infracción por equivalencia como el de la infracción por imitación ("imiten un invento con solicitud de

\footnotetext{
${ }^{58}$ Véase supra 2.4.1. letra c).
} 
VAN WEEZEL, Alex. "El delito de infracción de una patente por equivalencia o por imitación".

patente en trámite"), de modo que esta última sólo puede constatarse tras el examen de cada uno de los elementos o limitaciones, en orden a establecer la sustancialidad de las diferencias entre las reivindicaciones y los productos o procedimientos supuestamente infractores. Si el elemento (o la agrupación funcional de elementos singulares) que falta crea una diferencia sustancial, no existe imitación. Si el elemento (o la agrupación funcional de elementos singulares) que falta no crea una diferencia sustancial, la exigencia de triple identidad recogida en la regulación llevará a rechazar la equivalencia, pero ello no impedirá que se esté ante una imitación punible.

Dicho de otro modo, la protección contra imitaciones surte el efecto de morigerar la rigidez de la "regla de la totalidad de los elementos o limitaciones", lo que a su vez libera un campo donde es posible apreciar infracciones no literales punibles al margen de la equivalencia; sin embargo, dicha protección no autoriza a prescindir por completo de la regla, pues ello contraviene tanto la estructura de las relaciones entre equivalencia e imitación plasmadas en la Ley, como el mandato constitucional de determinación de los tipos penales, cuya vigencia es incompatible con el establecimiento de elementos normativos indeterminados (y, desde luego, también con la introducción de ellos por vía interpretativa). ${ }^{59}$ Desde el punto de vista de la garantía de tipicidad, el riesgo de indeterminación queda excluido si se interpreta el tipo de imitación -en perfecta armonía con el régimen de la equivalencia- integrándolo con el tenor de las reivindicaciones, con miras a un examen de sustancialidad de las diferencias; por el contrario, el riesgo de indeterminación se realiza si la imitación se establece sobre la base de un juicio global de semejanza.

La interpretación del ámbito propio de las imitaciones que resulta del análisis precedente es restrictiva, pues considera como imitación lo que en el derecho comparado se ha tenido en el pasado ( $\mathrm{y}$, en ocasiones, también en la actualidad) como equivalente a la invención patentada. Sin embargo, una interpretación del art. 52 letra d) de la Ley 19.039 que eximiera al intérprete de analizar la funcionalidad de cada uno de los elementos (o grupos de elementos) reivindicados y que, en cambio, le permitiera conformarse con un juicio global de semejanza, no sólo sería incompatible con el principio de tipicidad tal como se encuentra definido en el art. $19 \mathrm{~N}^{\circ} 3$ inciso final de la Constitución, sino también con la recepción normativa de la doctrina de los equivalentes y su proyección sobre las infracciones no literales por imitación.

e) Cuál es el objeto de la infracción, si la solicitud de patente en trámite evoluciona con el tiempo.

En los Estados Unidos se ha asentado la idea de que la equivalencia es una realidad objetiva, que se define mediante el juicio objetivo de un experto, y por lo tanto los conocimientos y el desarrollo tecnológico relevantes para apreciarla son los que existen al momento de la infracción, y no los que están disponibles al momento de la concesión de la

\footnotetext{
${ }^{59}$ En un sentido análogo al expresado por WOLF, Erik, Typen der Tatbestandsmäßigkeit. Vorstudien zur allgemeinen Lehre vom besonderen Teil des Strafrechts, Breslau: F. Hirt, 1931, p. 60, cuando hablaba de elementos normativos "subjetivos".
} 
Polít. crim. Vol. 8, No 15 (Julio 2013), Art. 5, pp. 170 - 209.

[http://www.politicacriminal.cl/Vol_08/n_15/Vol8N15A5.pdf]

patente. Desde otro punto de vista, al realizar su solicitud el inventor no está obligado a prever los desarrollos tecnológicos y científicos que pueden presentarse en el futuro. ${ }^{60}$

Si se aplicara en Chile un criterio análogo en materia de imitaciones punibles, resultaría que el pliego de reivindicaciones decisivo para definir el objeto de protección de la patente en trámite sería aquel que está vigente en el procedimiento cuando la infracción se comete. Se comprende fácilmente que, bajo estas condiciones, el ámbito objetivo de lo protegido resultaría intolerablemente incierto, por mucho que el infractor objetivo pueda excusarse por razones de índole subjetiva: error, falta de dolo (o "malicia", en la expresión legal). Además, podría ocurrir que un pliego intermedio contenga aún elementos no patentables de conformidad a la Ley, sea modificado en virtud de objeciones legítimas, etc.

Por lo tanto, lo más razonable es sostener que el pliego de reivindicaciones que fija el objeto de la protección frente a imitaciones es el pliego definitivamente aprobado y concedido por el INAPI. Ello es coincidente con el hecho de que la Ley no concede acciones al titular hasta que la patente se haya otorgado, y sólo en los términos del certificado al que se refiere el art. 48. De este modo se obtiene certeza acerca del objeto de eventuales infracciones.

\section{El estado de la técnica o arte previo como límite a la doctrina de los equivalentes y a las infracciones por imitación.}

Ni la protección frente a equivalentes, ni la que se concede en Chile frente a las imitaciones dejan sin efecto, sin embargo, los límites que impone el arte previo a los derechos de propiedad industrial. Lo que la doctrina suele llamar "arte previo", se encuentra definido en el Reglamento bajo el nombre de "estado de la técnica". Éste corresponde a "todo aquel conocimiento que ha sido colocado al alcance del público en cualquier parte del mundo, aunque sea totalmente desconocido en Chile, mediante una publicación en forma tangible, la venta o comercialización, el uso o cualquier otro medio, antes de la fecha de presentación de una solicitud o de la reivindicación de la prioridad de un derecho de propiedad industrial en Chile" (art. $2^{\circ}$ del Reglamento).

La jurisprudencia comparada -entre otras la alemana, británica, estadounidense y japonesaha reconocido en el estado de la técnica un límite importante a la aplicación de la doctrina de los equivalentes. Este límite, que tiene que ver con las características del procedimiento o producto acusado de infracción, consiste en que si bien el infractor no puede controvertir la concesión de la patente en un proceso cuyo objeto es enjuiciar la infracción de la misma, para que exista una infracción por equivalencia es necesario que el procedimiento objeto de la acusación no forme parte del estado de la técnica o constituya una variación obvia de ésta.

De esta manera se resguarda el interés público en un mejoramiento paulatino del estado de la técnica, lo que es particularmente importante cuando las invenciones patentadas o en trámite se encuentran muy próximas a dicho estado. En consecuencia, cuando la patente es

${ }^{60} \mathrm{KIEFF}$ et al., Principles of patent law, cit. nota $\mathrm{n}^{\circ} 18$, pp. 930, $936 \mathrm{y} \mathrm{ss.}$ 
VAN WEEZEL, Alex. "El delito de infracción de una patente por equivalencia o por imitación".

muy modesta en su nivel inventivo, en principio sólo se la puede infringir si es que se la reproduce en forma idéntica ( $\mathrm{y}$ no mediante el uso de equivalentes ni menos de imitaciones), o bien si se realiza una reproducción por equivalencia o una imitación que además contenga un aporte inventivo respecto del estado de la técnica. En buena parte de la literatura, esta limitación del arte previo es conocida como defensa Formstein, a raíz del caso del mismo nombre resuelto en 1986 por el Tribunal Federal alemán. ${ }^{61}$

El principio es, pues, muy simple en su núcleo: el acusado no ha incurrido en infracción aunque el artefacto o procedimiento cuestionado esté dentro del objeto de protección de una patente concedida o en trámite, si es que ese artefacto o procedimiento no constituye por sí mismo un producto o procedimiento patentable. La siguiente ilustración ${ }^{62}$ grafica el principio y sus relaciones tanto con la infracción literal como con las infracciones no literales por equivalencia y por imitación:

Fig. 1

defensa Formstein: no hay infracción

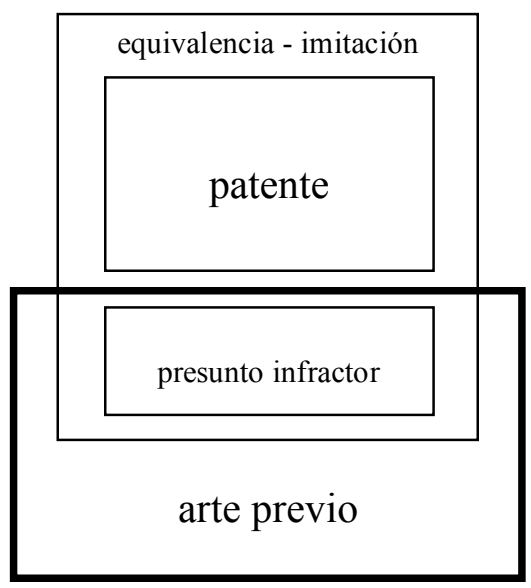

Fig. 2

infracción

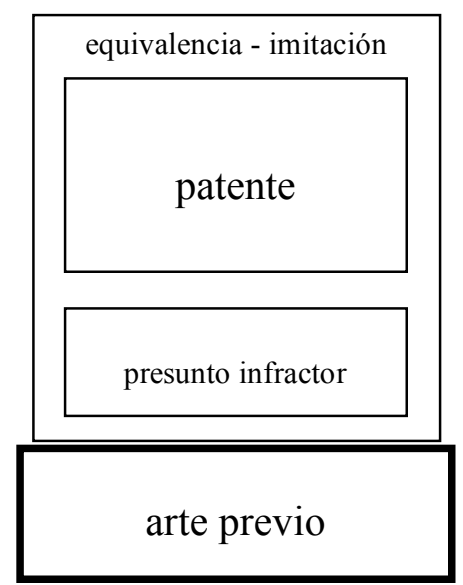

\subsection{La reivindicación hipotética.}

Aunque el principio es simple, en un caso concreto puede ser bastante complejo saber si existe un arte previo y hasta dónde éste puede restringir el rango de equivalentes. En el caso Wilson Sporting Goods Co. v. David Geoffrey \& Associates, ya citado, el Circuito Federal realizó el intento de responder a estas cuestiones sirviéndose de una "reivindicación hipotética". Se trata de formular una reivindicación (inexistente en la realidad) ajustada para comprender literalmente el producto acusado. Luego se debe preguntar si esta

\footnotetext{
${ }^{61}$ El origen de la doctrina, conocida como Formstein, es la sentencia de la $10^{\text {a }}$ Sala Civil del Tribunal Federal alemán, de 29.IV.1986 en el proceso X ZR 28/85, publicada en BGHZ 98, 12-24. Esta doctrina ha sido adoptada en lo fundamental en Reino Unido (caso "Merrell", de 1995), en Estados Unidos (parte de los fundamentos de la decisión en el caso Wilson Sporting Goods Co. v. David Geoffrey \& Assoc. [1990]), y en Japón (parte de los fundamentos de la decisión en el caso "Ball Spline", de 1998). Al respecto véase MUIR et

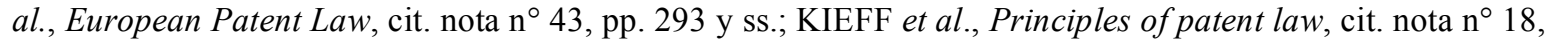
p. 939.

${ }^{62}$ La ilustración fue elaborada por Felipe Claro Swinburn.
} 
Polít. crim. Vol. 8, No 15 (Julio 2013), Art. 5, pp. 170 - 209.

[http://www.politicacriminal.cl/Vol_08/n_15/Vol8N15A5.pdf]

"reivindicación fantasma" habría sido aceptada por la oficina de patentes desde el punto de vista del estado de la técnica. Si la respuesta es negativa, entonces resultaría improcedente permitir al titular de la patente obtener esa cobertura en el contexto de un procedimiento penal y bajo la doctrina de los equivalentes. Si, en cambio, la reivindicación hipotética hubiera sido aprobada, entonces el estado de la técnica no impide la constatación de una infracción bajo la doctrina de los equivalentes. ${ }^{63}$

La fórmula de la reivindicación hipotética ha sido criticada tanto en la doctrina como en la propia jurisprudencia. ${ }^{64}$ Se ha dicho, por ejemplo, que resulta confusa desde el punto de vista de la prueba, pues en lugar de exigir a la acusación que pruebe la equivalencia respecto de una reivindicación real, se podría terminar obligando al acusado a probar que la reivindicación fantasma no hubiera sido aprobada por la oficina de patentes. El mismo Circuito Federal ha señalado que no se trata de una herramienta de uso obligatorio, sino que debe aplicarse sólo en la medida en que sea apropiada para el caso. ${ }^{65}$ Con esta advertencia, es claro que la fórmula puede ser de utilidad en la praxis para despejar dudas acerca de la posible infracción.

\subsection{La limitación del estado de la técnica en el contexto de la doctrina de los equivalentes.}

La limitación del arte previo surte efecto, adicionalmente, con respecto a la aplicación de la regla de la totalidad de los elementos. Pues la doctrina de Warner-Jenkinson, según la cual es preciso analizar elemento por elemento la equivalencia entre lo reivindicado y lo supuestamente infractor, podría llevar, tal como se anticipó, a que la construcción de las reivindicaciones se vuelva "ciega" ante ciertos elementos que forman parte del estado de la técnica y que se presentan en combinación con otros que sí poseen novedad.

Esta situación dio origen a un pronunciamiento expreso del Circuito Federal en cuanto a que la comparación debe realizarse entre el aparato o procedimiento acusado de infracción, considerado como un todo, y el arte previo o estado de la técnica. La "mera existencia de un elemento en el arte previo no impide automáticamente al titular de una patente identificar un ámbito de equivalencia suficiente para incluir bajo él al elemento correspondiente en el artefacto acusado de infracción" (Conroy v. Reebok Int'l, 14 F.3d 1570 [Fed. Cir. 1994]).

\subsection{El fundamento legal en Chile y su aplicación a las imitaciones.}

En Chile, el fundamento legal para la aplicación del estado de la técnica como límite a las infracciones no literales de una patente se encuentra en la combinación de los arts. 31, 32, 33 y 35 de la Ley, según los cuales las patentes otorgadas o en trámite sólo confieren protección hasta donde alcanza el valor inventivo de su objeto. Allí donde la Ley ha querido extender el objeto de protección, lo ha señalado expresamente, como ocurre en el art. 49 inciso $2^{\circ}$, según el cual "en las patentes de procedimiento, la protección alcanza a los productos obtenidos directamente por dicho procedimiento".

\footnotetext{
${ }^{63}$ KIEFF et al., Principles of patent law, cit. nota ${ }^{\circ} 12$, p. 940.

${ }^{64}$ ADELMAN, Patent Law, cit. nota ${ }^{\circ} 13$, pp. 741 y ss.

${ }^{65}$ MOORE et al., Patent Litigation and Strategy, cit. nota ${ }^{\circ} 15$, pp. 743 y ss.
} 
Si ya respecto de las infracciones no literales por equivalencia es indispensable una limitación como la que constituye el arte previo, ello se aplica con mayor razón aun a la protección más amplia que brinda la solicitud en trámite en contra de las imitaciones. Debido a su condicionalidad y a la incertidumbre de su objeto al tiempo de la conducta eventualmente infractora, resulta indispensable considerar un dispositivo que compatibilice la protección del invento cuya patente se tramita contra aplicaciones muy similares, por un lado, con el interés público en que no existan monopolios sobre el estado del arte o de la técnica, por el otro.

\subsection{Carga de la prueba.}

Es evidente que la carga de la prueba de la infracción pesa sobre la acusación. Pero cabe preguntarse a quién correspondería probar que la reivindicación hipotética sería aceptada por la oficina de patentes, es decir, que en el producto o procedimiento supuestamente infractor concurren todos los elementos como para resultar patentable (lo que permitiría afirmar la existencia de una infracción). En la sentencia Formstein del Tribunal Federal alemán (BGHZ 98, 12), el Tribunal Federal alemán dejó claramente establecido que la carga de la prueba en el sentido de que el aparato o procedimiento presuntamente infractor se encontraba dentro del estado de la técnica o del arte previo -es decir, que la reivindicación hipotética no era patentable y por tanto no hay infracción- corresponde al acusado. Nos parece que esta solución es coherente con los principios que orientan la carga de la prueba en el derecho chileno, donde, si bien corresponde probar los delitos y sus elementos a quien los imputa, al acusado se le exige que acredite aquellos extremos que resultan indispensables para su propia defensa en todos los casos en que se está prima facie ante una infracción (la denominada "carga subjetiva" de la prueba). Tal es la situación en que se encuentra, por ejemplo, la prueba relativa a la concurrencia de los presupuestos fácticos de las causas de justificación o, incluso, de ciertos aspectos fundamentales para la delimitación del riesgo permitido. ${ }^{66}$

Este mismo criterio se ha abierto paso en los Estados Unidos. Si bien en el caso Wilson la Corte Suprema de los Estados Unidos asignó al mismo acusador la carga de la prueba sobre la patentabilidad de la reivindicación fantasma, ${ }^{67}$ con posterioridad el Circuito Federal ha sugerido que le corresponde al acusado probar que el aparato supuestamente infractor se encontraba dentro del estado de la técnica (National Presto Indus., Inc. v. West Bend Co., 76 F.3d 1185 [Fed. Cir. 1996]).

\footnotetext{
${ }^{66}$ Pero incluso si se rechaza la idea de una "carga subjetiva" de la prueba, y se sostiene, por ejemplo, que "los defectos de las pruebas disponibles respecto de una cierta proposición sobre los hechos del caso que justifican una duda e impiden tenerla por probada bajo el estándar de prueba más allá de toda duda razonable, consisten en que ellas no logren eliminar o refutar alguna proposición fáctica alternativa plausible y compatible con la inocencia" (ACCATINO, Daniela, "Certezas, dudas y propuestas en torno al estándar de la prueba penal", Revista de Derecho de la Ponitificia Universidad Católica de Valparaíso XXXVII [2011], p. 507, destacado en el original), es necesario demostrar las condiciones de plausibilidad de la proposición fáctica alternativa; cfr. también WALTER, Tonio, "Die Beweislast im Strafprozeß”, Juristenzeitung 2006, pp. 340 y ss.

${ }^{67}$ HOLZMANN, Infringement of the United States Patent Right, cit. nota ${ }^{\circ} 28$, p. 102; MOORE et al., Patent Litigation and Strategy, cit. nota $\mathrm{n}^{\circ} 15$, p. 476.
} 
Polít. crim. Vol. 8, № 15 (Julio 2013), Art. 5, pp. 170 - 209.

[http://www.politicacriminal.cl/Vol_08/n_15/Vol8N15A5.pdf]

\section{Conclusiones}

La doctrina de los equivalentes -incluyendo sus limitaciones- es determinante en la obtención del equilibrio entre la certeza de la protección que brinda la patente y la restricción de dicha protección a lo que efectivamente constituye el invento. Este equilibrio se encuentra en la base del sistema de la propiedad industrial y la tensión entre sus dos extremos caracteriza al bien jurídico protegido por los delitos de infracción de una patente. Por tal razón, es imprescindible avanzar en el desarrollo de los contornos de la doctrina, que son al mismo tiempo los contornos de la existencia real del bien jurídico. En esta dirección, de lo expuesto precedentemente es posible concluir lo siguiente:

1. La definición de la infracción de una patente que es preciso constatar para aplicar los tipos penales establecidos en el art. 52 de la Ley 19.039 incluye el ámbito delimitado por la doctrina de los equivalentes. Esta doctrina ha sido desarrollada principalmente en el derecho comparado, pero ha sido recepcionada en Chile desde antiguo por la doctrina y la jurisprudencia y, más recientemente, por la normativa aplicable.

2. Los elementos fundamentales de la recepción de la doctrina de los equivalentes en Chile, y en particular el art. $2^{\circ}$ del Reglamento de la Ley 19.039, permiten concluir que, para afirmar la equivalencia, la acusación debe demostrar la presencia de cada elemento reivindicado o de su equivalente sustancial en el aparato acusado de infracción. Al analizar las invenciones elemento por elemento, ha de buscarse una triple identidad, en cuanto a la función que cumple el elemento en cuestión, la forma en que la cumple y el resultado obtenido por él. Por otro lado, el análisis de la equivalencia nunca puede eliminar o vaciar de contenido algún elemento de la reivindicación o su fundamento técnico.

3. Aparte de la infracción no literal por equivalencia, el ordenamiento jurídico chileno contempla el delito de imitación de un invento con solicitud de patente en trámite. La imitación se da allí donde prima facie, en el análisis elemento por elemento, se observa una equivalencia, pero el análisis detallado revela que no se cumple con la triple identidad en sentido estricto (es decir, allí donde aplicar la teoría de los equivalentes significaría eliminar por completo o vaciar de contenido algún elemento reivindicado). También la hay en los casos en que alguno o algunos de los elementos del infractor no coinciden exactamente con alguno o algunos de los elementos reivindicados, pero tales diferencias pueden considerarse insustanciales. Esto es válido incluso si la falta de sustancialidad de las diferencias se constata después de agrupar funcionalmente elementos singulares, tanto en el artefacto o procedimiento patentado como en el acusado de infracción. En cambio, nunca es posible sustituir el análisis comparativo singular de los elementos del invento patentado y del objeto o procedimiento acusado de infracción por un análisis de ambos considerados como un todo. El intérprete siempre debe analizar cada uno de los elementos -aunque sea para agruparlos funcionalmente- $\mathrm{y}$ no puede conformarse con un juicio general de semejanza. Si lo hiciera, contravendría tanto la estructura de las relaciones entre equivalencia e imitación plasmadas en la Ley y su Reglamento, como el mandato constitucional de determinación de los tipos penales, que es incompatible con el establecimiento de elementos normativos indeterminados. 
VAN WEEZEL, Alex. "El delito de infracción de una patente por equivalencia o por imitación".

4. Los límites generalmente reconocidos de la equivalencia son la regla de la totalidad de las limitaciones o elementos, el estoppel de la historia de la tramitación administrativa, el arte previo y la doctrina de la revelación al público. Se puede afirmar que, en Chile, la protección contra imitaciones surte el efecto de morigerar la rigidez de la regla de la totalidad de los elementos o limitaciones, lo que a su vez libera un campo donde es posible apreciar infracciones no literales punibles al margen de la equivalencia, con el límite señalado en la conclusión anterior. Por otra parte, en nuestro ordenamiento jurídico la historia administrativa de concesión de la patente juega un rol formalmente menor, pero que en la práctica puede ser muy relevante debido a la marcada accesoriedad del derecho penal de la propiedad industrial.

5. La limitación del arte previo -o defensa Formstein, en el contexto infraccional- es común a la equivalencia y a la imitación. Conforme a ella, el acusado no ha incurrido en infracción aunque el artefacto o procedimiento cuestionado esté dentro del objeto de protección de una patente concedida o en trámite, si es que ese artefacto o procedimiento no constituye por sí mismo un producto o procedimiento patentable. Esta defensa encuentra sustento en el ordenamiento jurídico chileno, que reconoce el estado de la técnica como límite a los derechos de propiedad industrial. 
Polít. crim. Vol. 8, No 15 (Julio 2013), Art. 5, pp. 170 - 209.

[http://www.politicacriminal.cl/Vol_08/n_15/Vol8N15A5.pdf]

\section{OBRAS CITADAS}

ACCATINO, Daniela, "Certezas, dudas y propuestas en torno al estándar de la prueba penal", Revista de Derecho de la Pontificia Universidad Católica de Valparaíso XXXVII (2011), pp. 483-511.

ADELMAN, Martin J. et al., Cases and materials on patent law, $3^{a}$ ed., St. Paul Minnesota: Thomson West, 2009.

BARDEHLE, Heinz, "Die Rolle der Äquivalente und des Erteilungsverfahrens bei der Bestimmung des Schutzbereichs von Patenten", Int'l Ass'n for the Protection of Intellectual Prop., Q175, Working Comm. Group Report (Germany) 3, disponible para los miembros de la AIPPI en https://www.aippi. org/download/commitees/175/GR175 germany.pdf [visitado el 08.03.2013].

BENEYTEZ, Luis, "Delitos relativos a la propiedad industrial" en: BACIGALUPO, Enrique (dir.), Curso de derecho penal económico, $2^{\mathrm{a}}$ ed., Madrid: Marcial Pons, 2005

CASTIÑEIRA, María Teresa, "El alcance de la protección penal de la propiedad industrial", en: SILVA SÁNCHEZ, Jesús-María, ¿Libertad económica o fraudes punibles? Riesgos penalmente relevantes e irrelevantes en la actividad económicoempresarial, Madrid: Marcial Pons, 2003.

Claro SOLAR, Luis, Explicaciones de Derecho Civil Chileno y Comparado, Tomo Sexto, De los bienes, Santiago, 1930.

FERNÁNDEZ, Fernando, "The non-obviousness requirement in the Chilean patent law. A critical assessment", Revista Chilena de Derecho, Vol. 38, N 3 (2011), pp. 487-510.

GONZÁLEZ RUS, Juan, Delitos contra el patrimonio y contra el orden socioeconómico (VIII). Delitos relativos a la propiedad intelectual e industrial, al mercado y a los consumidores, en: COBO DEL ROSAL, Manuel (coord.), Derecho penal español. Parte especial, $2^{\mathrm{a}}$ ed., Madrid: Dykinson, 2005.

HOEKMAN, Doneil John, Modern Judicial Interpretations of U.S. Patent Law, Santa Clara (California): Documech, 2009.

HOHMANN, Olaf, "Gedanken zur Akzessorietät des Strafrechts", en Zeitschrift für internationale Strafrechtsdogmatik, 1/2007, pp. 38 y ss.

HOLZMANN, Richard T., Infringement of the United States Patent Right: A Guide for Executives and Attorneys, Westport: Quorum Books, 1995.

JAKOBS, Günther, Strafrecht, Allgemeiner Teil. Die Grundlagen und die Zurechnungslehre, $2^{\text {a }}$ ed., Berlin: De Gruyter, 1991.

KIEFF, F. Scott et al., Principles of patent law: Cases and Materials, $4^{a}$ ed., New York: Thomson West, 2008.

LIANOS, Ioannis, "Las implicancias de una teoría regulatoria de la propiedad intelectual (PI) para el derecho de la libre competencia: visión desde Europa", Trad.: CASTRO, Sebastián, GRUNBERG, Jorge, Revista de Derecho Económico, № 75 (2010), pp. 205-283.

MARTÍNEZ-BUJÁN PÉREZ, Carlos, Derecho penal económico. Parte especial, $3^{\mathrm{a}}$ ed., Valencia: Tirant lo Blanch.

MASCAREÑAS, C.E., Los delitos contra la propiedad industrial, $2^{\mathrm{a}}$ ed., Barcelona: Librería Bosch, 1960. 
VAN WEEZEL, Alex. "El delito de infracción de una patente por equivalencia o por imitación".

MELOSSI, Andrés, "Interpretación de las patentes de invención. Doctrina de los equivalentes y su aplicación en Chile", en: MORALES, Marcos (coord.), Temas actuales de propiedad intelectual. Estudios en homenaje a la memoria del profesor Santiago Larraguibel Zavala, $2^{\text {a }}$ ed. Santiago: Abeledo Perrot, 2007, pp. 199-237.

MOORE, Kimberly et al., Patent Litigation and Strategy, $3^{a}$ ed., St. Paul, Minnesota: Thomson West, 2008.

MUIR, Ian et al., European Patent Law. Law and Procedure under the EPC and PCT, $2^{\mathrm{a}}$ ed., New York: Oxford University Press, 2002.

NENTWIG, Malte, en: ACHENBACH, Hans y RANSIEK, Andreas (editores), Handbuch Wirtschaftsstrafrecht, $3^{\mathrm{a}}$. ed., Heidelberg et al.: C.F. Müller, 2011, Parte XI.

RAYO, Jorge, Delitos contra la propiedad industrial, Tesis de Licenciatura, Universidad de Chile, 1945.

ROJAS, Luis, "Accesoriedad del derecho penal", en: VAN WEEZEL (editor), Humanizar y renovar el derecho penal. Estudios en memoria de Enrique Cury, Santiago: Legal Publishing, 2013, pp. 93-107.

SEGURA GARCÍA, María, "La protección penal de los derechos integrantes de la propiedad industrial", Cuadernos de Derecho Judicial N 10 (1998), pp. 13-66.

SONODA \& KOBAYASHI, "Doctrine of Equivalents in Japan after Supreme Court Decision in 1998 in Ball Spline Bearing Case 2(1999)", disponible en http://www.patents.jp/Archive/19980415-04.pdf [visitado el 05.03.2012].

TIEDEMANN, Klaus, Tatbestandsfunktionen im Nebenstrafrecht, Tübingen: Mohr Siebeck, 1969.

, Wirtschaftsstrafrecht. Besonderer Teil, $2^{\mathrm{a}}$ ed., Köln-München: Carl Heymanns Verlag, 2008.

TOSHIKO TAKENAKA, "The Doctrine of Equivalents in Japan", 6 CASRIP Publication Series: Rethinking International Intellectual Property 125 (2000), disponible en http://www.law.washington.edu/casrip/symposium/Number6/Takenaka.pdf [visitado el 05.03.2012].

VAN WEEZEL, Alex, "Principio de especialidad de las marcas y delito marcario", Gaceta Jurídica $\mathrm{N}^{\mathrm{o}} 315$ (2006), pp. 32-38.

WALTER, Tonio, “Die Beweislast im Strafprozeß”, Juristenzeitung 2006, pp. 340 y ss.

WOLF, Erik, Typen der Tatbestandsmäßigkeit. Vorstudien zur allgemeinen Lehre vom besonderen Teil des Strafrechts, Breslau: F. Hirt, 1931. 